\title{
Heart regeneration and repair after myocardial infarction - translational opportunities for novel therapeutics
}

\author{
Authors \\ Dr Thomas J Cahill1,2, Professor Robin P. Choudhury ${ }^{2,3}$ \& Professor Paul R. Riley ${ }^{1}$ \\ 1. Department of Physiology, Anatomy \& Genetics, University of Oxford \\ Sherrington Building \\ Oxford, OX1 3PT, U.K.
}

2. Department of Cardiovascular Medicine, University of Oxford John Radcliffe Hospital

Oxford, OX3 9DU, U.K.

3. Oxford Acute Vascular Imaging Centre, University of Oxford John Radcliffe Hospital, OX3 9DU, U.K.

\section{Correspondence to}

Professor Paul R. Riley

BHF Professor of Regenerative Medicine

Chair of Development and Cell Biology

Department of Physiology, Anatomy and Genetics

Sherrington Building

University of Oxford

South Parks Road

Oxford OX1 3PT

paul.riley@dpag.ox.ac.uk 


\section{Abstract}

Current therapies for heart failure after myocardial infarction (MI) are limited and non-curative. Although regenerative approaches are receiving significant attention, clinical efforts involving transplantation of presumed stem and progenitor cells have largely failed. Recent studies of endogenous heart regeneration in model organisms such as the zebrafish and neonatal mouse are yielding novel mechanistic insights into the roles of cardiomyocyte proliferation, resident stem cell niches, neovascularisation, the immune system and the extracellular matrix. These findings have revealed novel pathways which might be therapeutically targeted to stimulate repair following $\mathrm{MI}$, and provided lessons to guide future efforts toward heart regeneration through cellular reprogramming or cardiomyocyte transplantation. 


\section{Introduction}

Heart failure (HF) is the consequence of cardiomyocyte death or dysfunction, most commonly caused by myocardial infarction (MI), hypertension, valve disease, infiltration, infection, chemotherapy or genetic cardiomyopathy. ${ }^{1,2} \mathrm{HF}$ is a global disease challenge which affects an estimated 38 million people worldwide. ${ }^{3}$ Despite strides forward in the management of acute MI, HF remains common and the incidence may be increasing due to improved early survival with primary percutaneous coronary intervention. ${ }^{4,5}$ Healthcare costs associated with HF exceed $\$ 30$ billion annually in the USA alone and are projected to increase to almost $\$ 70$ billion by $2030 .{ }^{6} \mathrm{HF}$ is a leading cause of hospitalization, adverse quality of life, and death, and a new diagnosis carries a worse prognosis than many cancers, with a survival rate of only $50 \%$ at 5 years.

Current therapies to prevent or delay progression of HF are limited. Conventional pharmacotherapy targets the maladaptive counter-regulatory mechanisms activated by left ventricular dysfunction (Box 1). This approach has yielded blockbuster agents over the last 20 years, including inhibitors of the renin-angiotensin system, the mineralocorticoid receptor, the sympathetic nervous system, and most recently, the natriuretic system (Figure 1). ${ }^{7,8}$ While these drugs reduce mortality, they fail to address the underlying loss of cardiomyocytes and vasculature and are intrinsically non-curative.

Regeneration of the heart by reconstitution of the cardiomyocyte substrate is a tantalising and potentially entirely disruptive approach to HF. Regeneration is seen widely across the animal kingdom, and can occur in humans, for example after liver injury. To date, clinical efforts towards cardiac regeneration have focused on cell-based therapies, including bone marrowderived cells, mesenchymal stem cells and presumed cardiac progenitor cells (Table 1).9,10 While these studies have met safety endpoints, the effect on cardiac function has been small or negligible, which has prompted a search for novel approaches. Insights from endogenous heart regeneration in animal models such as the zebrafish and neonatal mouse are now yielding new understanding of innate mechanisms for complex organ repair. This includes the origins of new cardiomyocytes after injury, control of cardiomyocyte proliferation in 
development and ageing, and the roles of developmental stem cell niches such as the epicardium. ${ }^{11,12}$

In this Review, we will describe recent insights into the biology of heart regeneration gained in preclinical animal models and extrapolate these to a next generation of regenerative strategies for $\mathrm{HF}$, including methods for augmentation of intrinsic repair, cell reprogramming and extrinsic cardiomyocyte replacement. Key steps needed to translate informed biology to novel therapeutic approaches and compounds, adapt existing clinical trial design and enhance interactions between scientists, clinicians and the pharmaceutical industry will be outlined. 


\section{Discovery of heart regeneration [H1]}

Organ regeneration has long been recognized. In 1686, lizard tail regeneration was demonstrated to the Paris Academy of Sciences, and the first scientific reports of regeneration in Hydra were published by Abraham Trembley in the mid-18 $8^{\text {th }}$ century.

Regeneration of the injured heart was first recognised in amphibians and has now been described in a number of teleost fish and amphibians. ${ }^{13}$ The two-chambered heart of the zebrafish (Danio rerio) regenerates after damage caused by surgical resection of the cardiac apex, cryoinjury, cardiomyocyte ablation, or hypoxia-reoxygenation. ${ }^{14-17}$ Urodele amphibians, including the axolotl and newt, are also capable of complete heart regeneration. In both fish and amphibians, functional cardiomyocytes re-populate the injury site and transient scar is resolved over a variable period of 60-180 days depending on the injury mechanism. ${ }^{13,18,19}$

Although previously thought to be restricted to fish and amphibians, Porrello et al reported heart regeneration in the neonatal mouse in $2011 . .^{20,21}$ After resection of the cardiac apex or surgical coronary artery ligation (to induce MI), regeneration occurred over $\sim 21$ days leaving only very minor residual scarring at the site of the ligature. Interestingly, this capacity for regeneration was restricted to a temporally privileged window of the first seven days after birth.

The revelation that regeneration can occur in the neonatal mouse has ignited the field and suggests that regenerative repair is not a unique program lost to mammals in evolution. Whilst regeneration in the postnatal setting may involve a repurposing of the ongoing growth response, it remains highly valuable as a means to identify trophic pathways to promote regeneration in the adult. Furthermore, several intriguing (albeit low level) studies support the concept of a temporally privileged period of regenerative repair in humans. These include a case report of a newborn infant with a large anterior myocardial infarction, which healed by regeneration with full functional recovery. ${ }^{22}$ Other case reports of functional regeneration after cardiac injury in infants, and a lack of scarring in children after cardiac surgery for congenital heart disease, support the concept of age-dependent regeneration in the human heart. ${ }^{23,24}$ 


\section{Mechanisms of heart regeneration [H1]}

Regeneration is a finely orchestrated process which has parallels to organ formation during embryonic development, requiring control of cell division, differentiation, migration, integration and maturation. ${ }^{25}$ Compared to development, regeneration from injury is complicated by the need to clear damaged or dead tissue, regulate inflammation, suppress overactive fibrosis, and reconstitute and integrate only a subsection of cardiomyocytes, extracellular matrix, blood vessel and lymphatic systems ${ }^{26}$ Studies of heart regeneration in key genetic model organisms, the zebrafish and the mouse, have heralded a number of insights into the underlying biological mechanisms of these processes.

\section{Cardiomyocyte regeneration [H2]}

Replacement of cardiomyocytes to restore structural and functional integrity is the sine qua non of heart regeneration. Identifying the source(s) of new cardiomyocytes and mechanisms controlling cardiomyocyte proliferation is critical to understanding the mechanisms of regeneration and to direct therapeutic strategies for humans.

\section{Sources of cardiomyocytes in endogenous regeneration [H3]}

In principle, new cardiomyocytes might be derived from the existing cardiomyocyte pool (either directly from mature cardiomyocytes or an intermediate cell type) or alternatively from a progenitor cell population, either resident in the heart or located remotely. Seminal studies in the zebrafish and mouse have addressed this question using genetic lineage tracing, employing the tamoxifen-inducible Cre-LoxP system to irreversibly label cardiomyocytes with a fluorescent reporter protein prior to injury. ${ }^{27}$ Once the label is activated, all cardiomyocytes and their progeny express the fluorescent reporter, meaning that if new cardiomyocytes are labelled they have originated from the pre-existing pool. If not, it can be assumed that they have been derived from a non-cardiomyocyte progenitor. Two studies using this approach in the zebrafish have shown that almost all ( 95\%) new cardiomyocytes after injury are labelled, suggesting that cells in the pre-existing cardiomyocyte pool are capable of re-entering the cell cycle, dividing and migrating in order to effect regeneration. ${ }^{28,29}$ In the mouse, new cardiomyocytes formed during ageing and neonatal heart regeneration are also derived from 
the pre-existing cardiomyocyte pool..$^{21,30}$ In the infarcted non-regenerating adult mouse heart, some data support a minor contribution of a non-cardiomyocyte progenitor population (e.g. ckit+ cells) to the development of new cardiomyocytes, but this remains controversial. ${ }^{31,32}$

The concept of regeneration driven primarily by existing cardiomyocytes is a paradigm shift. Many of the first generation cell-therapy trials (Table 1) were inspired by the concept of bonemarrow derived progenitors, which had been reported to differentiate into cardiomyocytes, but this has been progressively discredited..$^{33-35}$ The benefits of bone marrow mononuclear cells and mesenchymal stem cells seen in some clinical studies (Table 1) are increasingly ascribed to paracrine effects. Understanding whether human mature cardiomyocytes can proliferate, and the mechanisms by which this is controlled, is now a major research focus.

\section{Cardiomyocyte proliferation in development, ageing and injury [H3]}

Cardiomyocytes in mice and humans proliferate during heart development in utero and early postnatal life. After birth, most cardiomyocytes exit the cell cycle, a variable subset ( $25 \%$ in humans) undergoing a further cycle of nuclear division without cell separation (cytokinesis), resulting in binucleation. ${ }^{36}$ In humans, the adult heart has thus traditionally been considered incapable of further cell division, with growth being achieved by hypertrophy. In fact, increasing evidence suggests that cardiomyocytes do renew in the human heart, albeit at a low level. Relying on integration of carbon-14 into DNA during Cold War nuclear testing, Bergmann et al estimated that cardiomyocyte self-renewal occurs at a rate of $1 \%$ per year for adults aged 25 years, decreasing to $0.45 \%$ by 75 years. ${ }^{37}$ Histological analysis of the human heart has identified phosphorylated histone $\mathrm{H} 3$, a marker of mitosis, in adults up to the age of approximately 20 years. ${ }^{38}$ However, despite the apparent capacity for renewal, MI fails to activate effective proliferation. In the adult mouse, using co-registration of cardiomyocyte fluorescent labelling and $\left[{ }^{15} \mathrm{~N}\right]$ thymidine labelling of DNA replication, Senyo et al reported that only $3 \%$ of infarct zone cardiomyocytes initiate DNA replication and nuclear division. Furthermore, whilst these cells became binucleated, almost none underwent cytokinesis to form a new daughter cell. ${ }^{30}$ 


\section{Control of cardiomyocyte proliferation [H3]}

Environmental cues in the post-natal environment have been implicated in proliferative arrest of mammalian cardiomyocytes. After birth, the heart transitions from the relatively hypoxic intrauterine environment to normoxia, which is associated with a shift from glycolysis to oxidative phosphorylation, increased mitochondrial content and activity, production of reactive oxygen species and cardiomyocyte cell cycle arrest. ${ }^{39}$ Scavenging of reactive oxygen species prolongs the neonatal regenerative window, whereas hyperoxia shortens it. During regeneration, re-activation of cell cycle activity is associated with hypoxic activation of Hif$1 \alpha .40$ Other factors have been implicated in the loss of proliferative capacity postnatally, including upregulation of p38 MAPK and Meis1.41 42 Meis1, a member of the three amino acid loop extension transcription factor family, promotes cell cycle arrest via activation of the cyclin-dependent kinase inhibitors p15, p16 and p21. Inhibition of Meis1 extends the regenerative window in neonates and is capable of reactivating the cell cycle in adults.

Many of the emerging ligands and signalling pathways which govern cardiomyocyte proliferation in regeneration are familiar from developmental biology (Figure 2). Neuregulin1 (NRG1), an agonist for the ErbB2 and ErbB4 receptor tyrosine kinases of the epidermal growth factor receptor family, is a key mitogen during heart development. ${ }^{43,44}$ It is reactivated in perivascular cells during zebrafish heart regeneration and overexpression enhances cardiomyocyte proliferation even in the uninjured heart. ${ }^{45}$ The transcription factor Hand2 is critical to cardiomyocyte development from the second heart field, with zebrafish mutants having a reduction in cardiomyocytes and mice showing abnormalities in the right ventricle and outflow tract region. ${ }^{46,47} \mathrm{Hand} 2$ is upregulated in the injured zebrafish ventricle, and overexpression is sufficient to drive cardiomyocyte proliferation. ${ }^{48}$ Similarly, Gata4, a zinc finger transcription factor known to regulate cardiomyocyte differentiation, migration, hypertrophy and survival, is required for neonatal mouse heart regeneration, acting via FGF16 to stimulate proliferation. ${ }^{49}$ The Hippo pathway, comprising series of proteins which regulate the transcription factor YAP and its co-activator TAZ, is an evolutionarily conserved regulator of cell proliferation, growth, viability and organ size. ${ }^{50}$ Forced expression of YAP in development leads to hyperproliferation and cardiac enlargement, and in mouse 
regeneration, YAP promotes proliferation acting via insulin-like growth factor and Wnt signalling pathways..$^{51,52}$ Finally, as in development, regeneration requires chromatin remodelling by Brg1, which controls proliferation through pro-proliferative Bmp10 and inhibition of p57kip2. ${ }^{33}$ Inhibition of Brg, or other SWI/SNF components such as baf60c and baf180, leads to blunted proliferation and failed regeneration. ${ }^{54}$

Despite these insights, whether a mature mammalian cardiomyocyte can re-enter cell cycle and progress through to cytokinesis is unclear. In the zebrafish, cardiomyocytes are mononuclear and relatively "primitive", and this appears to be a critical factor determining their ability to divide. Proliferation of the mononuclear cardiomyocyte population can be induced by NRG1 treatment after MI in mice, and based on nuclearity, the adult human heart might be more 'regenerative' than the mouse since it contains a higher proportion of mononuclear cardiomyocytes. ${ }^{55}$ In addition, distinct subsets of cardiomyocytes may have differing abilities to proliferate: in zebrafish, the outermost 'cortical' zone proliferates early and rapidly in regeneration. ${ }^{56}$ Cardiomyocyte proliferation requires cellular 'de-differentiation', defined by increased intercellular separation and loss of sarcomeric and Z-disc structure. ${ }^{28}$ Dedifferentiation has been observed in the mammalian heart, and may be triggered by oncostatin M, a macrophage-derived cytokine related to IL6, but is poorly characterised at a molecular level. ${ }^{57}$

Research priorities in the mammalian heart include identifying and tracking the key cardiomyocyte sub-population(s) capable of division in the adult, based on ploidy or other discriminating features. Characterising the markers and transcriptional pathways of cardiomyocytes undergoing dedifferentiation, replication, migration and maturation would be valuable and is achievable with single cell sequencing approaches. ${ }^{58}$ The precise mechanisms which direct cardiomyocytes to undergo cell division as opposed to polyploidization (which seems to suppress further cell cycle-entry) also remain poorly understood. ${ }^{59}$ In parallel, understanding the hierarchy, relative importance and overlap of extrinsic cues would help prioritise therapeutic targets. For example, alongside the soluble ligands discussed above, the autonomic nervous system is emerging as a regulator of 
cardiomyocyte proliferation and may be potentially ripe for adjunctive targeting. ${ }^{60,61}$

\section{Neovascularisation: the role of the epicardium [H2]}

Whilst PPCl is effective at restoring coronary blood flow in the major epicardial vessels following MI, failure to perfuse the microcirculation (microvascular occlusion, $\mathrm{MVO}$ ) is common and is associated with poor wound healing, ventricular remodelling, heart failure and reduced overall survival. ${ }^{62} \mathrm{MVO}$ is multifactorial and occurs due to endothelial cell death, inflammation, and physical plugging by thrombotic or plaque debris. Restoration of effective myocardial perfusion by regeneration or repair of the coronary microcirculation, comprising vascular endothelium, smooth muscle, fibroblast and pericytes, will be essential to achieve heart regeneration.

\section{Coronary formation during development [H3]}

Coronary formation during development is a blueprint for formation of new vessels. Coronary endothelial cells arise primarily from the sinus venosus, with an additional contribution from the inner lining of the heart, the endocardium, which generates coronary endothelium for the interventricular septum. ${ }^{63-65}$ The program of coronary vascular formation is directed by the epicardium, also known as the visceral pericardium, which acts as both a source of trophic factors and progenitor cells. ${ }^{66}$ Formed at embryonic day 9.75 in the mouse (human Carnegie stage 11), the epicardium is an epithelial sheet which envelops the growing heart. ${ }^{67}$ Epicardial-derived cells (EPDCs) invade the underlying myocardium and undergo epithelialto-mesenchymal transition (EMT), giving rise to pericytes, smooth muscle and adventitial and interstitial fibroblasts. ${ }^{63,68} 69$ The epicardium also begins a signalling pas de deux with the myocardium, secreting growth factors supporting vasculogenesis and mitogens which support cardiomyocyte proliferation. ${ }^{66}$ Physical or genetic ablation (through deletion of epicardial genes such as Wt1) leads to defects in coronary vessel formation and impaired cardiomyocyte proliferation. ${ }^{70,71}$ 
The epicardium is quiescent in the adult heart, but is reactivated and expands in response to injury. ${ }^{72,73}$ Reactivation is associated with expression of an embryonic gene profile and recapitulation of its developmental functions, supporting repair and neovascularisation. Ablation of tcf21 positive cells in the epicardium after ventricular resection in the zebrafish led to a reduction in cardiomyocyte proliferation, delayed neovascularisation and incomplete regeneration at 30 days. ${ }^{74}$ In adult mice, priming of the epicardium prior to injury with the small peptide thymosin $\beta 4$ (T $\beta 4$ ), or treatment with epicardial cell conditioned media, improves neovascularisation and functional outcomes after MI. ${ }^{75-77}$ Similarly, stimulation of the epicardium with $T \beta 4$ in the neonatal mouse can extend the temporal window for regeneration. ${ }^{78}$

The precise mechanisms of coronary revascularisation following injury are not well defined. There is evidence to support both local proliferation of endothelial cells and a contribution from a remote stem cell source, the endothelial progenitor cell, a controversy which is discussed in detail elsewhere. ${ }^{79}$ In the neonatal mouse heart, neovascularisation is achieved primarily by formation of large collateral arteries which bypass the ligation site. These derive from pre-existing arteries through a process of arteriogenesis, rather than arterialization of the pre-existing capillary network. ${ }^{80}$ Clues from non-cardiac injury models (e.g. zebrafish fin and retina) suggest that neovascularisation during regeneration is dependent on classical angiogenic signalling mechanisms involving VEGFR, HIF-1, and Cxcl12. ${ }^{81-83}$

Neovascularization is supported by the epicardium via a number of secreted factors, including retinoic acid, fibroblast growth factors, VEGF-A and SDF1. ${ }^{84,85}$ Blockade of Fgf signalling in zebrafish leads to a failure of EMT and neovascularisation (discussed further below), in turn leading to failed regeneration. ${ }^{73}$ In the mouse, reactivation of epicardial EMT following MI contributes several cell lineages to support repair. By inducible labelling of the Wt1 population, EPDCs have been shown to contribute to fibroblasts, myofibroblasts, smooth muscle cells and adipocytes. ${ }^{77,86}$ Whether the reactivated epicardium can contribute other cell types, specifically cardiomyocytes or endothelial cells, is debated. When pre-primed with exogenous T $\beta 4$, the epicardium can generate extremely limited numbers of cardiomyocytes, 
but this does not occur without priming and is not seen in zebrafish regeneration. ${ }^{75,87-89}$ Finally, an emerging mechanism relates to epicardial-immune cell cross-talk. The epicardium is required for seeding of the heart with tissue-resident macrophages during embryonic development, and macrophages colocalise with the epicardium following injury. ${ }^{90}$ Recently, the epicardium has been shown to mediate an immunosuppressive response to Ml via modulation of cytokines which promote regulatory T-cell recruitment to the heart. ${ }^{91}$ In the mouse, genetic knock-out of epicardial YAP/TAZ led to persistent inflammation, widespread fibrosis, heart failure and death following Ml. ${ }^{91}$

The epicardium is increasingly recognised to be a highly heterogeneous cell population containing both mesenchymal and haematopoietic cells within specialised clusters. ${ }^{92}$ Dissecting apart their respective roles, and separating the paracrine and progenitor cell components of the epicardial response, will require improved markers for different subpopulations. Recently at least three new subpopulations have been reported in zebrafish, including a role for novel genes such as caveolin $1 .{ }^{93}$ Understanding how the epicardial response is modulated in the setting of regeneration in comparison to scar formation, for example to repress fibroblast formation, is a key research requirement in order to optimally harness its therapeutic effects.

\section{Inflammation and immune system activation [H2]}

MI leads to extensive cell death and is a potent activator of inflammation. ${ }^{94}$ In mice and humans, inflammation is linked to repair through a biphasic immune response: an early proinflammatory phase characterised by release of cytokines and recruitment of neutrophils and monocytes, followed by a reparative phase with resolution of inflammation, activation of myofibroblasts and deposition of collagen-based scar. ${ }^{95,96}$ This process is patterned and under tight spatiotemporal regulation. Macrophages, for example, have diverse functions through the course of injury including pro-inflammatory cytokine production, phagocytosis of necrotic cell debris, pro-angiogenic signalling, activation of fibroblasts and remodelling of the ECM. ${ }^{97,98}$ Improved cell surface markers and transcriptional profiling are helping to define the 
identity and function of specific monocyte-macrophage, neutrophil and T cell subsets in the injured heart. ${ }^{99-101}$

Inflammation is not a barrier to tissue regeneration and in fact may provide the initial proregenerative cues. In the zebrafish, for example, brain injury activates acute inflammation which is sufficient to drive neural proliferation via leukotriene $\mathrm{C} 4 .{ }^{102}$ The cellular immune response to injury is has also been directly implicated in healing by regeneration. ${ }^{103} \mathrm{In}$ regenerating muscle, infiltrating cells including macrophages, eosinophils and T-regulatory cells influence activation of satellite cells and fibroadipogenic progenitors to specify production of new myofibres. ${ }^{104,105} 106$ Macrophages also commit endothelial progenitors to capillary formation, suppressing an alternative EMT pathway. ${ }^{107}$ After liver injury, macrophage secretion of Wnt3a controls lineage differentiation of hepatic progenitor cells to produce hepatocytes. ${ }^{108}$ Similarly, macrophage production of Wnt7b in the injured kidney is required for regeneration. ${ }^{109}$

Inflammation and the immune response has also been linked to heart regeneration. Activation of inflammation stimulates cardiomyocyte proliferation in the neonatal heart, and blockade of IL6 or cardiomyocyte STAT3, its downstream effector, blocks heart regeneration after apical resection. ${ }^{110}$ In the neonatal $\mathrm{MI}$ model, macrophages are actively recruited to the neonatal heart and treatment with clodronate liposomes to ablate macrophages blocks regeneration through inhibition of angiogenesis. ${ }^{111}$ Divergent roles for distinct macrophage subsets are emerging, notably between tissue-resident macrophages, seeded to visceral organs during embryonic development, in comparison to those which derive from circulating monocytes, from bone marrow or splenic reservoirs, during acute inflammation. Using a cardiomyocyteablation model, Lavine et al found that depletion of resident macrophages in the neonatal heart led to reduced cardiomyocyte and endothelial cell proliferation, interstitial fibrosis and chamber dilatation. ${ }^{112}$ In contrast, inhibition of CCR2+ macrophages, derived from monocytes, preserved embryonic subsets and improved myocardial repair. ${ }^{112}$

Multiple injury models suggest that inflammatory signalling is required as a trigger to induce 
cell proliferation or differentiation of progenitors to restore the lost tissue substrate. The precise mechanisms behind the divergent outcome of inflammation in regeneration and scar forming models, however, remain to be fully elucidated. The capacity for tissue regeneration appears to be inversely correlated with evolutionary complexity of the immune system, which has led to the suggestion that a component of the mammalian immune response might be a barrier to regeneration. ${ }^{113}$ Dissecting apart pro-regenerative signals from those which drive fibrosis or scar deposition, or the mechanisms by which the same signals drive divergent healing, will require detailed comparisons of immune-cell signalling in regenerative and scarforming models. In addition, further characterisation of the interplay between immune cell subsets, fibroblasts, endothelial cells and cardiomyocytes is required. Potential therapeutic approaches to harness the regenerative potential of inflammation are discussed below. 


\section{Role of the extracellular matrix [H2]}

The extracellular matrix (ECM) consists of an organised and dynamic meshwork of proteins. ${ }^{114}$ Previously thought of as an inert structural scaffold, the ECM is now recognised to have a number of biological effects and influences cell proliferation, migration, lineage specification, intercellular signalling and growth factor presentation. ${ }^{115}$ Control of the extracellular matrix is a critical component of regeneration. In the newt limb, upregulation of ECM-remodelling matrix metalloproteinases (MMPs) occurs within hours, and inhibition of MMPs blocks regeneration. ${ }^{116}$ This is associated with early deposition of a primitive ECM consisting of hyaluronic acid, fibronectin and tenascin- $\mathrm{C}$, and downregulation of collagen. ${ }^{117}$ Production and remodelling of ECM components also occurs in scar-based healing, but this 'scarring' ECM is compositionally distinct and appears to be directed by immune-cell control of fibroblasts to produce collagen. ${ }^{118}$

In the heart, differences in ECM structure may be an important aspect underlying the interspecies capacity for regeneration. While fish have a non-compacted, spongy myocardium designed to function at low arterial blood pressure, the 4-chambered adult mammalian heart is highly compacted in a rigid matrix. ${ }^{119}$ In the neonatal mouse, stiffening and maturation of the ECM is correlated with cardiomyocyte cell cycle arrest and in vitro, modulation of ECM compliance directly influences the ability of cardiomyocytes to undergo proliferation and cytokinesis. ${ }^{120}$ Interestingly, if the failing human heart is off-loaded by implantation of a left ventricular assist device, cell cycle re-entry has been observed - an effect which might be mediated by permissive ECM changes. ${ }^{121}$

The ECM also has direct biological effects on cardiomyocytes. The decellularised zebrafish ECM can induce cardiomyocyte proliferation and cardioprotection in the mouse heart, an effect which is mediated via the ErbB2 receptor. ${ }^{122}$ Functional ECM components are emerging from candidate approaches and unbiased screens. Fibronectin, derived from the epicardium after injury, stimulates zebrafish heart regeneration. ${ }^{123,124}$ Periostin, a matricellular protein, promotes cell cycle activation in mononucleated cardiomyocytes, but also activates fibroblasts. ${ }^{125}$ Small and large animal studies of periostin have shown improved healing after 
MI, but at the expense of increased fibrosis. ${ }^{126,127}$ Hyaluronic acid and its receptor hyaluronan-mediated motility receptor are required for EMT and zebrafish regeneration. ${ }^{128}$

The roles of the ECM during regeneration and scar formation are still emerging, and thus much of the work is descriptive and early stage. The compositional differences in the ECM during regeneration and scar formation, and the biological activity of these proteins on downstream cell types, are not yet fully defined. Transcriptional profiling of fibroblasts, the major source of ECM components, and mass spectrometry of the ECM in regeneration versus scar formation, would begin to address these questions. It remains unclear to what extent ECM components can drive regeneration in vivo in an otherwise non-regenerative environment, and whether the ECM represents a standalone therapeutic target in endogenous regeneration. Harnessing the biological effects of the ECM is also of value to cell therapy strategies, where survival, localisation, and engraftment of cells may be augmented using patches or bioscaffolds with engineered matrix properties. ${ }^{129}$

\section{Scar formation and degradation [H2]}

Regeneration and scar formation lie at opposite ends of the spectrum of repair. From an evolutionary perspective, it is unclear whether regenerative capacity was lost accidentally, as a neutral trait, or whether it was selected against. While it seems intuitive that regeneration would confer a survival and reproductive advantage, costs associated with energy, time or interim function (e.g. electrical stability) may have made it advantageous to heal by rapid scar formation ${ }^{130,131}$

Following acute MI, scar is rapidly laid down in the mammalian heart by activated myofibroblasts. In the short term this scar is critical to providing mechanical strength and prevention of ventricular rupture. Fibroblasts are originally derived from the epicardium and endocardium during embryonic development through EMT. ${ }^{132}$ Using a periostin inducible Cre line for lineage tracing, Kanisicak et al showed that activated myofibroblasts derive from tissue-resident (tcf21+) fibroblasts, producing large quantities of extracellular matrix components such as collagen, and deactivating following resolution of injury. ${ }^{133}$ In the 
reparative phase, fibroblast activation following $\mathrm{MI}$ is multifactorial but intricately linked to macrophage cytokine regulation, for example by TGF $\beta$ and CTGF. Interestingly, TGF $\beta$ has been identified as a key pro-regenerative cytokine in the axolotl - but the mechanisms by which fibroblast activation are suppressed are not clear. ${ }^{134}$

The relationship between scar deposition and regeneration is complex. It has been proposed that these two events are diametrically opposed and compete in order to achieve organ repair, with collagen deposition directly inhibitory to regeneration. ${ }^{135}$ However, knock-down of scar formation by astrocytes following spinal cord injury is not sufficient to induce axonal regrowth. ${ }^{136}$ Furthermore, in the cryoinjury model in the zebrafish heart, even despite extensive scar deposition during the first 3 weeks following injury, regeneration still occurs, with progressive scar removal and replacement with cardiomyocytes over time..$^{19}$ The finding that scar is not necessarily a barrier to regeneration has enormous therapeutic implications, and suggests that the regenerative program does not necessarily need to be established in the early injury phase. 


\section{Strategies for therapeutic regeneration [H1]}

Efforts towards heart regeneration encompass a broad spectrum of approaches including cell therapy, biomaterials, tissue engineering, reprogramming, and modulation of endogenous repair (Figure 3a). This section will focus primarily on therapeutic strategies which exploit insights from developmental biology, including specification or programming of the cardiomyocyte lineage, and endogenous regeneration.

It should be noted that distinct approaches will be required for patients post-MI and patients with chronic HF. MI provides a dynamic environment of repair in which endogenous pathways can be modulated towards regeneration. In contrast, in the setting of stable HF, strategies to directly provide new cardiomyocytes should be the focus. Current and future strategies for production of new cardiomyocytes and targeting of endogenous repair are discussed in turn (Figure 3a, b).

\section{Cardiomyocyte replacement [H2]}

Activation of cardiomyocyte proliferation [H3]

Initial attempts to reactivate cardiomyocyte proliferation were inspired by insights into cell cycle regulation by the cyclin and cyclin-dependent kinase (Cdk) system. ${ }^{36}$ Cyclin-Cdk complexes modulate members of the retinoblastoma gene family (Rb, p107, p130), which in turn lead to release of E2F transcription factors which activate genes for DNA synthesis. Overexpression of cyclin $\mathrm{B} 1-\mathrm{CDC} 2^{137}$ or knockdown of the cyclin-dependent kinase inhibitors p21, p27 and p57 by RNA interference, are effective at inducing DNA replication in vitro. ${ }^{138}$ In vivo, overexpression of cyclin A2, D1 or D2 stimulates DNA synthesis, and cyclin D2 overexpression leads to improved repair following Ml. ${ }^{139,140}$ Other approaches have included knockout of tumour suppressor genes $\mathrm{Rb}(\mathrm{Rb} 1)$ and $\mathrm{p} 130$, and direct targeting of the $\mathrm{E} 2 \mathrm{~F}$ transcription factor family. ${ }^{141}$ Combinatorial reprogramming of cardiomyocytes informed by microarray approaches to define the proliferative state have proved to be more effective at achieving improved repair. ${ }^{142}$ In general, however, these approaches have triggered relatively modest DNA replication, very limited cytokinesis and consequently little new cardiomyocyte mass. 
Therapeutic targeting of upstream signalling pathways regulating proliferation may reduce the risk of teratogenicity which is inherent in directly targeting the cell cycle. For example, exogenous injection of NRG1 activates proliferation of mononucleated cardiomyocytes via the ErbB4 tyrosine kinase receptor and PI3K, leading to improved repair following experimental MI. ${ }^{55}$ Similarly, delivery of FGF1 with blockade of the p38 MAPK pathway, a key mediator of cardiomyocyte differentiation, promotes myocardial repair following injury. ${ }^{143} \mathrm{~A}$ recent porcine MI study showed that percutaneous intramyocardial injection of microparticles loaded with NRG1 and FGF1 is effective at inducing improvement in LV function following MI, with reduced remodelling and improved angiogenesis (Table 2). ${ }^{144}$ However, the growth response is exquisitely regulated: in the zebrafish, Notch activation is required for cardiomyocyte proliferation, but hyperactivation of Notch inhibited rather than promoted heart regeneration. ${ }^{145} \mathrm{~A}$ phase I study of recombinant Neuregulin $1 \beta 3$ (cimaglermin alfa) in patients with chronic heart failure has recently shown early promise, with evidence for safety and preliminary findings suggesting an improvement in LV function at 90 days (Table 3). ${ }^{146}$

Therapeutic cardiomyocyte proliferation can also be induced by micro-RNA targeting. Screening of a whole genome miRNA library, identified 40 miRNAs which increased both DNA synthesis and cytokinesis in vitro, two of which, has-miR-590 and has-miR-199a, stimulated cardiac regeneration in adult mice after experimental MI. ${ }^{147}$ Similarly, overexpression of the miR302-367 family is sufficient to improve regeneration following adult MI, acting via repression of the Hippo pathway. ${ }^{148}$ In contrast, the miR-15 family is upregulated post-natally, correlating with the shutdown of cardiomyocyte proliferative capacity. Delivery of anti-miR15 led to increased proliferation in both the cardiomyocyte and non-myocyte compartments after $\mathrm{Ml}$ at day 21 , resulting in significant improvement in functional outcome..$^{21}$

A major outstanding challenge in the field is that reactivation of the cardiomyocyte cell cycle is frequently not followed by completion of cytokinesis to generate new daughter cells. Identifying therapeutic factors, miRNAs or small compounds which can drive bona fide cytokinesis would benefit greatly from improved readouts of completed cell division. Efforts 
towards this include the anilin-GFP model which provides a potential mechanism for discriminating cytokinesis from endoreduplication. ${ }^{149}$ Despite these recent advances, accurately quantifying dividing cardiomyocytes within the adult mammalian heart is extremely difficult and would benefit greatly from further research focus.

De novo cardiomyocytes by cellular (re)programming [H3]

Production of de novo cardiomyocytes by directed differentiation of embryonic stem (ES) cells, or reprogramming of differentiated non-myocyte cells (e.g. fibroblasts) to a cardiomyocyte fate has revolutionised therapeutic approaches to regeneration. ${ }^{26,150}$ Interestingly, reprogramming by transdifferentiation is a strategy deployed in endogenous regeneration, first recognised in the newt lens over 100 years ago. ${ }^{151}$ The zebrafish utilises transdifferentiation of alpha to beta cells to regenerate its islets, and in the heart can reprogram atrial to ventricular cardiomyocytes after injury. ${ }^{152,153}$ Reprogramming of hepatocytes to biliary endothelial cells has been described in murine liver regeneration. ${ }^{154}$

Large numbers of human cardiomyocytes can be produced by differentiation of ES cells. Chong et al demonstrated that transplanted hESC-CMs (at a dose of $1 \times 10^{9}$ per heart) survive and contribute new myocardium to the macaque heart after direct injection two weeks following MI. ${ }^{155}$ Although a powerful proof of concept, evidence of functional improvement was lacking and ventricular arrhythmias were recorded in all animals, suggesting that significant hurdles with electrical integration remain before human trials could safely be undertaken (Table 2). Furthermore, ethical concerns exist about use of embryonic tissue, and as an allogeneic product, recipients would require lifelong immunosuppression to prevent rejection of the cells.

Reprogramming of fibroblasts to cardiomyocytes offers potential advantages: a nonimmunogenic cell product, derived from the patient's own cells, and no requirement for the destruction of embryos. Inspired by the revolutionary description of induced pluripotency by Yamanaka, reprogramming approaches were initially undertaken ex vivo, relying on an intermediate induced pluripotent stem (iPS) cell stage. ${ }^{156}$ Transplanting iPS-derived 
cardiomyocytes in a non-human primate model, Shiba et al showed improvement in function following cell transplant, but also a significant ventricular arrhythmia rate (Table 2). ${ }^{157}$ However, production of an autologous cell product is expensive, subject to variability, and has restricted commercial opportunity. In addition to biological hurdles, the logistical and financial barriers to clinical use of autologous cell therapies are extremely challenging. Current cell numbers in the macaque trials have been of the order of $10^{8}-10^{9}$ cells, with at least an order of magnitude higher required for humans. The infrastructure and running costs of good manufacturing production at this scale, ideally embedded within or close to clinical cardiac centres, appear prohibitive.

The discovery that delivery of three cardiac developmental transcription factors, Gata4, Mef2c and Tbx5 could drive direct reprogramming of fibroblasts into cardiomyocytes, without an intermediate cell stage, has opened the door to the concept of reprogramming in vivo. ${ }^{158,159} \mathrm{~A}$ number of additional factors which improve the efficiency of reprogramming have now been identified, most notably Hand2. ${ }^{160}$ This approach requires no cell product, obviating the need for complex manufacturing. Proof of concept for in vivo reprogramming has now been demonstrated in mice, with transdifferentiated cells expressing sarcomeric proteins, forming gap junctions, and driving sustained improvement in ventricular function. ${ }^{161-164}$ Substantial challenges remain, including achieving selectivity of targeting to cardiomyocytes, reprogramming human cells which have stable epigenetic modifications, and achieving maturation of structure and function in reprogrammed cells.

\section{Neovascularisation \& lymphangiogenesis [H2]}

Strategies aimed at neovascularisation in MI have been somewhat frustrated in recent years by the failed promise of vascular endothelial growth factor (VEGF-A). Despite a number of animal studies showing efficacy from the recombinant protein or gene therapy with VEGF-A, the double blind EUROINJECT-ONE and NORTHERN clinical trials failed to show benefit. ${ }^{165,166}$ Attempting to reactivate more comprehensive developmental programs of coronary vessel formation, including targeting retained adult cell types that previously contributed to the developing coronaries, including the coronary sinus (sinus venosus- 
derived), endocardium and epicardium is a more attractive strategy for invoking neovascularization post-MI.

The epicardium in particular has emerged as a viable target and the development of in vitro systems for culture of human epicardium from human pluripotent stem cells will facilitate both biological understanding of the heterogeneity of the epicardium and small molecule screening for activating compounds. ${ }^{167}$ Recently, epicardial FSTL1 was identified as a key anti-apoptotic and proliferative factor promoting myocardial regeneration after injury. Application of a patch containing recombinant human FSTL1 improved long-term cardiac function in both rodent and swine models of myocardial infarction (Table 2). ${ }^{168}$ Furthermore, Zangi et al showed that intracardiac injection of a modified RNA (modRNA) encoding VEGF-A led to enhanced epicardial progenitor activation and improved functional outcome after MI. ${ }^{169}$ Functionally, VEGF-A modRNA promoted differentiation of EPDCs towards an endothelial (and in small numbers cardiomyocyte) cell fate. ${ }^{169}$

Clinical translation would benefit greatly from the ability to image the epicardium in vivo, and emerging technologies using PET, SPECT and molecular imaging to demonstrate angiogenesis will guide future trials. ${ }^{170}$ The endocardium continues to provide further endothelium for vessel formation for a short period during postnatal growth and might be reactivated in adulthood to enhance neovascularisation. ${ }^{171}$ Interestingly, experimental $\mathrm{MI}$ in mice has recently been shown to activate endothelial remodelling on the endocardial surface, leading to outgrowth of pre-existing coronary vessels and de novo arteriogenesis. ${ }^{172}$

Stimulation of new lymphatic vessel formation, lymphangiogenesis, is another emerging strategy to augment repair. The cardiac lymphatics remain poorly understood but are important for transport of interstitial fluid and trafficking of immune cells. ${ }^{173}$ Following MI, endogenous repair mechanisms activate lymphangiogenesis in mice and humans, a response which is required for clearance of oedema and resolution of inflammation. ${ }^{174}$ In rodents, augmentation of lymphangiogenesis by stimulation of VEGF-C signalling, the principal cytokine mediator of lymphatic formation during development, improves healing, 
reduces fibrosis and preserves myocardial function. ${ }^{175,176}$ The precise mechanisms underlying this are poorly understood but may relate to clearance of oedema and resolution of inflammation. 


\section{Immunomodulation [H2]}

Components of functional pathways, which can loosely be termed "inflammation", are intricately linked to healing following MI. A number of unsuccessful clinical trials of immunosuppressive agents (e.g. methylprednisolone, immunoglobulin, pexelizumab, anakinra; see Table 3) suggest that blunt inhibition of inflammation is not effective. ${ }^{177}$ Successful immunomodulation is likely to require both more nuance stratification of patients based on known activation (or inhibition) of specific pathways, coupled with identification and successful in vivo targeting of specific immune cell subsets, or pathways, to bring about beneficial repair. For example, inhibition of the CCR2+ monocyte population mobilised after MI using nanoparticle-delivered anti-CCR2 siRNA led to reduced injury and cardiac remodelling in mice. ${ }^{178}$ Transplantation of specific immune cell populations is a strategy being tested in other diseases: autologous macrophages are being trialled for regression of liver fibrosis ${ }^{179}$, and infusion of T-regulatory cells has shown efficacy in reduction of inflammation. Furthermore, understanding the differences of the immune response in the setting of scar formation compared to regeneration will shed light on precise pathways which can be modulated to enhance regeneration without compromising repair. In the chronic HF patient, immunomodulation is unlikely to be sufficient to induce regeneration. However, immunosuppression or induction of tolerance will be required to prevent rejection of allogeneic cardiomyocyte cell therapies, or vectors used to deliver a reprogramming cocktail.

\section{Fibrosis inhibition [H2]}

Inhibition of pro-fibrotic signalling in the setting of chronic HF has been suggested to account for some of the existing benefits of beta-blockers, angiotensin converting enzyme inhibitors, angiotensin receptor blockers and statins. A number of novel anti-fibrotic compounds are emerging and have recently been reviewed in the context of cardiovascular disease. ${ }^{180}$ Inhibition of scar formation after MI may have a complementary role to stimulation of endogenous repair or cell therapy, but without effective replacement of cardiomyocytes, remains critical to prevent cardiac rupture. Targeting late 'reactive' fibrosis in the uninjured myocardium, however, may reduce ventricular remodelling and progression to heart failure. ${ }^{181}$ 
For example, in addition to its effects on cardiomyocyte proliferation, NRG1 administered between 7-35 days following Ml reduced fibrosis and remodelling in swine through inhibition of myofibroblast transdifferentiation.and TGF $\beta$ signalling. ${ }^{182}$ Inhibition of chymase, which stimulates fibroblast activation after injury, reduced fibrotic area and improved survival following $\mathrm{MI}$ in small animal models. ${ }^{183,184}$ In rats, blockade of platelet derived growth factor (PDGF) receptor signalling with imatinib selectively inhibited fibrosis in the non-infarcted myocardium. ${ }^{185}$ Other prospective anti-fibrotic strategies in early stage studies include inhibitors of Wnt and histone deacetylases, and modulation of relaxin signalling (Figure $3 b) .{ }^{180}$ Prior to clinical trials in humans, an improved understanding of the heterogeneity of human post-MI healing is required, to allow targeting of anti-fibrotic therapies to groups at highest risk. For example, the use of advanced imaging and novel biomarkers of inflammation and fibrosis in the early phase of MI may identify outlier patient subpopulations who could then be targeted with specific therapies. 


\section{Translational challenges and considerations [H1]}

The last decade of clinical cell therapy trials have provided important lessons for the design and translation of future regenerative therapies. ${ }^{186,187}$ Issues related to the use of animal models, drug discovery approaches, patient selection, and clinical trial design will be discussed in turn.

\section{Limitations of animal models [H2]}

Animal models have unquestionable value as a route to novel biological insights, and there is extensive species conservation in regenerative signalling pathways such as Notch, TGF $\beta$, and JAK/STAT. ${ }^{188}$ From a translational perspective, however, there is a pressing need to improve the filtering of therapeutic targets and compounds prior to human studies. Many recent clinical trials of compounds targeting cardiac repair have shown limited efficacy (Table 3) and this has led to questions regarding the validity of animal models for assessing novel therapeutic strategies.

For regenerative therapies, a key problem inherent to existing animal studies is the use of young, healthy, homogeneous populations which lack the comorbidities or drug confounders typically associated with human patients. Age is inversely correlated with capacity for repair, with older mice demonstrating impaired wound healing after MI. ${ }^{189}$ In young animals, the 'bar' to improved repair is low, leading to false positive results and subsequent failed large animal or human studies. Development of highly non-regenerative animal models, such as aged rodents or pigs, might help reduce false positive studies prior to human trials.

\section{Drug discovery [H2]}

Focused drug discovery approaches to cardiac regeneration are complicated by the breadth of therapeutic strategies which persist in the academic arena, ranging from cell replacement, to reprogramming, to stimulation of endogenous regeneration (Table 2; Figure 3a). To address this, a move towards use of phenotypic screens, in vivo discovery and combination approaches will be required, with underlying biological insights used for target deconvolution. For example, screening for cardiomyocyte cell cycle reactivation in vivo using the FUCCI 
fluorescent reporter in zebrafish has been used to identify compounds targeting the Hedgehog, insulin-like growth factor and TGF $\beta$ pathways which effectively stimulate cell cycle re-entry. ${ }^{190}$ Furthermore, the 'FunSel' screening approach, whereby a cDNA library of the mouse secretome is targeted to cardiomyocytes in vivo using an adenoviral vector, has been applied to identify cardioprotective factors. ${ }^{191}$ Targeted sequencing to identify factors which are enriched after MI revealed that cardiomyocytes transfected with ghrelin improved cell survival after injury.

Once novel screening systems are established, partnerships with pharma should be established early in order to access screening libraries and improve the process of lead generation and optimization. Many paradigms which are effective in vitro or in pre-clinical models may of course fail to translate into the clinic. Assessment of compounds across multiple assays, or screening to assess the cumulative benefit of targeting of multiple parallel pathways for a given endpoint (for example, cardiomyocyte proliferation) may result in improved clinical efficacy downstream. ${ }^{192,193}$

\section{Delivery systems for regenerative therapies [H2]}

Targeting the heart is achievable through a combination of local delivery, biomaterial adjuncts and biological selectivity. For delivery, advances in catheter technology have made transendocardial injection, subepicardial access and intracoronary injection available by percutaneous, minimally-invasive approach. ${ }^{194}$ Surgical approaches by median sternotomy may be reasonable for proof of principle but are not realistic for the frail, comorbid HF population at large. Alongside delivery, major advances have been made in the field of biomaterials and bioscaffolds. ${ }^{129}$ Pre-seeded scaffolds, patches or injectable hydrogels have been shown to improve retention and survival of transplanted cells. ${ }^{195}$ For non-cell based approaches, delivery of factors within hydrogels or coated on microparticles can prevent rapid clearance or degradation. ${ }^{196}$ Local delivery and retention must be complemented by biological targeting (e.g. targeted liposomes, exosomes, or viral vectors) or biological selectivity for cardiomyocyte pathways. The risks of off-target effects are greatest for pro-proliferative or reprogramming approaches, which may disrupt remote cell function or be tumorigenic. ${ }^{197}$ 


\section{Patient selection [H2]}

Targeting therapies to selected patient groups will be key to the success of future regenerative therapy trials. Two distinct groups with separate biological and logistical challenges are patients with acute $\mathrm{MI}$ and patients with chronic HF.

The acute MI population is attractive for regenerative therapies which modulate or harness existing repair pathways, for example factors to promote cardiomyocyte proliferation or angiogenesis, epicardial targeting, immunomodulation or inhibition of fibrosis. The gain from such therapies might be expected to be greatest in young patients without comorbidities, in whom the barrier to endogenous regeneration is lowest. However, identifying precisely which MI patients to target is difficult as accurate predictors of future HF are lacking. Although age, diabetes, coronary physiology or imaging parameters (e.g. oedema, haemorrhage or microvascular obstruction) are predictors of final infarct size in cohorts at large, it remains difficult to accurately predict future HF events for a given patient. Practically, this means it may be difficult to justify the use of the highest-risk interventions (e.g. cell reprogramming) in patients.

Better identification of patients at risk of $\mathrm{HF}$ is required: emerging possibilities for enhanced characterisation derive from novel, mechanistically relevant biomarkers, including exosome characterisation, miRNA profiling and cellular transcriptomics. ${ }^{94}$ The goal is to develop diagnostics that provide quantifiable data on therapeutically relevant targets, which can be used to recruit patients to specific therapies. As noted in the cancer field, it seems likely that optimal characterisation will require approaches that combine imaging and panels of biomarkers for mechanistic staging.

In patients with chronic HF, the disease is established and in those with severely impaired left ventricular function and NYHA III-IV symptoms, the prognosis is extremely poor. As such, regenerative strategies which carry higher risk may be reasonable. Implantable cardioverter defibrillators are already indicated in this patient group to protect from arrhythmia and 
therefore cardiomyocyte cell therapy, reprogramming or cell patches, which may be arrhythmogenic, should be targeted at this cohort. The subgroup of patients on LVAD therapy as a bridge to heart transplant should also be recruited, as cardiac tissue may become available (at heart transplantation) to examine biological endpoints such as cell engraftment.

\section{Clinical trial design [H2]}

Regenerative therapies require re-evaluation of their clinical trial paradigm. ${ }^{198}$ Early trials of cell therapies have been small, heterogeneous, and subject to small study effect, in which subsequent studies fail to reproduce an apparently large effect. Improvements in trial design, particularly at the phase II stage, have the potential to reduce this problem. ${ }^{199}$ Wherever possible, phase II clinical studies should be designed to demonstrate a defined biological effect as a surrogate for efficacy. This might include angiogenesis, evidence of engraftment, or cell cycle re-entry, and in turn needs development and validation of novel imaging strategies for regeneration. ${ }^{200}$ This key step would allow biological insights to be correlated with clinical outcomes, in order to prioritise some therapies for large-scale, placebo controlled trials. These should ideally be carried out as part of consensus regenerative medicine networks such as the Cardiovascular Cell Therapy Research Network, which has been instrumental in organising large studies to show that BMMNCs in acute $\mathrm{Ml}$ or ischaemic cardiomyopathy do not improve LV function. Furthermore, there is increasing recognition of reporting issues with cell therapy trials, with over 600 reporting discrepancies identified across 49 trials. ${ }^{201}$ Of concern, the number of discrepancies correlated with the reported effect size in the trial. There is a need for standardization of cell characterisation, handling, methodology and reporting practice (akin to PRISMA or CONSORT) for trials.

\section{Conclusions}

Novel regenerative therapies inspire great hope amongst patients, scientists, physicians and the media. Although this excitement can be warranted, it can easily lead to exaggeration of actual benefits. Balancing the needs of a desperate patient population with the requirements for scientific rigour is challenging. Guidelines from the International Society for Stem Cell Research specifically warn against the dangers of hype as novel therapies emerge. ${ }^{202,203}$ 
Progress with regenerative therapies is likely to be incremental and iterative rather than a quantum leap.

While complete regeneration of the infarcted heart is the end goal, marginal gains in cardiomyocyte number, neovascularisation or scar reduction are a realistic first step and would have therapeutic value. The emerging biology of endogenous regeneration and cardiomyocyte biology is exposing a multiplicity of therapeutic targets which might be exploited by conventional small molecule approaches, recombinant factors, microRNAs, reprogramming or cell transplantation. Improving the commercialisation of regenerative therapies requires closer partnership of scientists, spin-outs, pharmaceutical industry and clinical trialists. There is a role for pharma in early partnership with scientists to test compound libraries in novel in vitro or in vivo screens. Improved pre-clinical models, patient selection and design of early clinical studies to establish biological efficacy in human subjects will help streamline a next generation of regenerative therapy trials. At the national level, governmental support is required, through facilitation of regulation and funding for incubator/facilitator organisations such as the Cell Therapy Catapult (U.K.) and the Centre for Commercialization of Regenerative Medicine (Canada) and CellCAN in Canada. ${ }^{230}$ 


\section{REFERENCES}

1. Roger, V.L. Epidemiology of Heart Failure. Circulation Research 113, 646 (2013).

2. Cahill, T.J., Ashrafian, H. \& Watkins, H. Genetic cardiomyopathies causing heart failure. Circ Res 113, 660-675 (2013).

3. Braunwald, E. The war against heart failure: the Lancet lecture. The Lancet 385, 812824 (2015).

4. Velagaleti, R.S., et al. Long-Term Trends in the Incidence of Heart Failure After Myocardial Infarction. Circulation 118, 2057 (2008).

5. Ezekowitz, J.A., et al. Declining In-Hospital Mortality and Increasing Heart Failure Incidence in Elderly Patients With First Myocardial Infarction. Journal of the American College of Cardiology 53, 13-20 (2009).

6. Heidenreich, P.A., et al. Forecasting the Impact of Heart Failure in the United States. Circulation: Heart Failure 6, 606 (2013).

7. Katz, A.M. The "Modern" View of Heart Failure. Circulation: Heart Failure 1, 63 (2008).

8. Jhund, P.S. \& McMurray, J.J.V. The neprilysin pathway in heart failure: a review and guide on the use of sacubitril/valsartan. Heart 102, 1342 (2016).

9. Kloner, R.A. Current State of Clinical Translation of Cardioprotective Agents for Acute Myocardial Infarction. Circulation Research 113, 451 (2013).

10. Nguyen, P.K., Rhee, J. \& Wu, J.C. Adult stem cell therapy and heart failure, 2000 to 2016: A systematic review. JAMA Cardiology 1, 831-841 (2016).

11. Yester, J.W. \& Kühn, B. Mechanisms of Cardiomyocyte Proliferation and Differentiation in Development and Regeneration. Current Cardiology Reports 19, 13 (2017).

12. Karra, R. \& Poss, K.D. Redirecting cardiac growth mechanisms for therapeutic regeneration. The Journal of Clinical Investigation 127, 427-436 (2017).

13. Vivien, C.J., Hudson, J.E. \& Porrello, E.R. Evolution, comparative biology and ontogeny of vertebrate heart regeneration. Regenerative Medicine 1, 16012 (2016).

14. Gonzalez-Rosa, J.M. \& Mercader, N. Cryoinjury as a myocardial infarction model for the study of cardiac regeneration in the zebrafish. Nat. Protocols 7, 782-788 (2012).

15. Wang, J., et al. The regenerative capacity of zebrafish reverses cardiac failure caused by genetic cardiomyocyte depletion. Development 138, 3421 (2011).

16. Parente, V., et al. Hypoxia/Reoxygenation Cardiac Injury and Regeneration in Zebrafish Adult Heart. PLOS ONE 8, e53748 (2013).

17. Poss, K.D., Wilson, L.G. \& Keating, M.T. Heart Regeneration in Zebrafish. Science 298, 2188 (2002).

First definitive report of heart regeneration 
18. Witman, N., Murtuza, B., Davis, B., Arner, A. \& Morrison, J.I. Recapitulation of developmental cardiogenesis governs the morphological and functional regeneration of adult newt hearts following injury. Developmental biology 354, 67-76 (2011).

19. González-Rosa, J.M., Martín, V., Peralta, M., Torres, M. \& Mercader, N. Extensive scar formation and regression during heart regeneration after cryoinjury in zebrafish. Development 138, 1663 (2011).

20. Porrello, E.R., et al. Transient Regenerative Potential of the Neonatal Mouse Heart. Science 331, 1078-1080 (2011).

\section{First report of mammalian heart regeneration}

21. Porrello, E.R., et al. Regulation of neonatal and adult mammalian heart regeneration by the miR-15 family. Proceedings of the National Academy of Sciences 110, 187192 (2013).

22. Haubner, B.J., et al. Functional Recovery of a Human Neonatal Heart After Severe Myocardial Infarction. Circulation Research (2015).

23. Fratz, S., et al. Long-Term Myocardial Scarring After Operation for Anomalous Left Coronary Artery From the Pulmonary Artery. The Annals of Thoracic Surgery 92, 1761-1765 (2011).

24. Tsang, V., et al. Late donor cardiectomy after paediatric heterotopic cardiac transplantation. The Lancet 374, 387-392.

25. Carlson, B.M. Some principles of regeneration in mammalian systems. The Anatomical Record Part B: The New Anatomist 287B, 4-13 (2005).

26. Xin, M., Olson, E.N. \& Bassel-Duby, R. Mending broken hearts: cardiac development as a basis for adult heart regeneration and repair. Nat Rev Mol Cell Biol 14, 529-541 (2013).

27. Kretzschmar, K. \& Watt, Fiona M. Lineage Tracing. Cell 148, 33-45.

28. Jopling, C., et al. Zebrafish heart regeneration occurs by cardiomyocyte dedifferentiation and proliferation. Nature 464, 606-609 (2010).

\section{New cardiomyocytes in the regenerating heart are derived from the existing cardiomyocyte pool}

29. Kikuchi, K., et al. Primary contribution to zebrafish heart regeneration by gata4+ cardiomyocytes. Nature 464, 601-605 (2010).

\section{New cardiomyocytes in the regenerating heart are derived from the existing cardiomyocyte pool}

30. Senyo, S.E., et al. Mammalian heart renewal by pre-existing cardiomyocytes. Nature 493, 433-436 (2013).

31. Ellison, Georgina M., et al. Adult c-kit+ Cardiac Stem Cells Are Necessary and Sufficient for Functional Cardiac Regeneration and Repair. Cell 154, 827-842.

32. van Berlo, J.H. \& Molkentin, J.D. An emerging consensus on cardiac regeneration. Nat Med 20, 1386-1393 (2014).

33. Orlic, D., et al. Bone marrow cells regenerate infarcted myocardium. Nature 410, 701705 (2001). 
34. Murry, C.E., et al. Haematopoietic stem cells do not transdifferentiate into cardiac myocytes in myocardial infarcts. Nature 428, 664-668 (2004).

\section{Landmark study refuting the concept of bone marrow-derived progenitor cells as a source of new cardiomyocytes in the mouse}

35. Balsam, L.B., et al. Haematopoietic stem cells adopt mature haematopoietic fates in ischaemic myocardium. Nature 428, 668-673 (2004).

36. Ahuja, P., Sdek, P. \& MacLellan, W.R. Cardiac Myocyte Cell Cycle Control in Development, Disease, and Regeneration. Physiological reviews 87, 521 (2007).

37. Bergmann, O., et al. Evidence for Cardiomyocyte Renewal in Humans. Science 324, 98 (2009).

\section{Identification and quantification of cardiomyocyte replication in the human heart using carbon-14 dating}

38. Mollova, M., et al. Cardiomyocyte proliferation contributes to heart growth in young humans. Proceedings of the National Academy of Sciences 110, 1446-1451 (2013).

39. Puente, Bao N., et al. The Oxygen-Rich Postnatal Environment Induces Cardiomyocyte Cell-Cycle Arrest through DNA Damage Response. Cell 157, 565-579 (2014).

40. Kimura, W., et al. Hypoxia fate mapping identifies cycling cardiomyocytes in the adult heart. Nature 523, 226-230 (2015).

41. Engel, F.B., et al. p38 MAP kinase inhibition enables proliferation of adult mammalian cardiomyocytes. Genes \& Development 19, 1175-1187 (2005).

42. Mahmoud, A.I., et al. Meis1 regulates postnatal cardiomyocyte cell cycle arrest. Nature 497, 249-253 (2013).

\section{Identification of Meis1 as an inhibitor of the cardiomyocyte cell cycle}

43. Lee, K.-F., et al. Requirement for neuregulin receptor erbB2 in neural and cardiac development. Nature 378, 394-398 (1995).

44. Gassmann, M., et al. Aberrant neural and cardiac development in mice lacking the ErbB4 neuregulin receptor. Nature 378, 390-394 (1995).

45. Gemberling, M., Karra, R., Dickson, A.L. \& Poss, K.D. Nrg1 is an injury-induced cardiomyocyte mitogen for the endogenous heart regeneration program in zebrafish. elife 4, e05871 (2015).

46. Yelon, D., et al. The bHLH transcription factor hand2 plays parallel roles in zebrafish heart and pectoral fin development. Development 127, 2573 (2000).

47. Srivastava, D., et al. Regulation of cardiac mesodermal and neural crest development by the bHLH transcription factor, dHAND. Nat Genet 16, 154-160 (1997).

48. Schindler, Y.L., et al. Hand2 elevates cardiomyocyte production during zebrafish heart development and regeneration. Development 141, 3112 (2014).

49. Yu, W., et al. GATA4 regulates Fgf16 to promote heart repair after injury. Development 143, 936 (2016).

50. Zhou, Q., Li, L., Zhao, B. \& Guan, K.-L. The Hippo Pathway in Heart Development, 
Regeneration, and Diseases. Circulation Research 116, 1431 (2015).

51. Heallen, T., et al. Hippo Pathway Inhibits Wnt Signaling to Restrain Cardiomyocyte Proliferation and Heart Size. Science 332, 458 (2011).

\section{Identification of the Hippo pathway as a key mediator of cardiomyocyte proliferation}

52. Xin, M., et al. Hippo pathway effector Yap promotes cardiac regeneration. Proceedings of the National Academy of Sciences 110, 13839-13844 (2013).

53. Hang, C.T., et al. Chromatin regulation by Brg1 underlies heart muscle development and disease. Nature 466, 62-67 (2010).

54. Xiao, C., et al. Chromatin-remodelling factor Brg1 regulates myocardial proliferation and regeneration in zebrafish. Nature communications 7, 13787 (2016).

55. Bersell, K., Arab, S., Haring, B. \& Kühn, B. Neuregulin1/ErbB4 Signaling Induces Cardiomyocyte Proliferation and Repair of Heart Injury. Cell 138, 257-270 (2009).

56. Gupta, V. \& Poss, K.D. Clonally dominant cardiomyocytes direct heart morphogenesis. Nature 484, 479-484 (2012).

57. Kubin, T., et al. Oncostatin M Is a Major Mediator of Cardiomyocyte Dedifferentiation and Remodeling. Cell Stem Cell 9, 420-432 (2011).

58. Di Talia, S. \& Poss, Kenneth D. Monitoring Tissue Regeneration at Single-Cell Resolution. Cell Stem Cell 19, 428-431 (2016).

59. Walsh, S., Pontén, A., Fleischmann, B.K. \& Jovinge, S. Cardiomyocyte cell cycle control and growth estimation in vivo - an analysis based on cardiomyocyte nuclei. Cardiovascular Research 86, 365-373 (2010).

60. White, I.A., Gordon, J., Balkan, W. \& Hare, J.M. Sympathetic Reinnervation Is Required for Mammalian Cardiac Regeneration. Circulation Research 117, 990 (2015).

61. Mahmoud, A.I., et al. Nerves Regulate Cardiomyocyte Proliferation and Heart Regeneration. Developmental cell 34, 387-399 (2015).

62. Regenfus, M., et al. Six-Year Prognostic Value of Microvascular Obstruction After Reperfused ST-Elevation Myocardial Infarction as Assessed by Contrast-Enhanced Cardiovascular Magnetic Resonance. The American Journal of Cardiology 116, 1022-1027 (2015).

63. Red-Horse, K., Ueno, H., Weissman, I.L. \& Krasnow, M.A. Coronary arteries form by developmental reprogramming of venous cells. Nature 464, 549-553 (2010).

\section{Coronary vessels originate from the sinus venosus during development}

64. Tian, X., et al. Subepicardial endothelial cells invade the embryonic ventricle wall to form coronary arteries. Cell Res 23, 1075-1090 (2013).

65. Zhang, H., et al. Endocardium Minimally Contributes to Coronary Endothelium in the Embryonic Ventricular Free Walls. Circulation Research 118, 1880-1893 (2016).

66. Masters, M. \& Riley, P.R. The epicardium signals the way towards heart regeneration. Stem Cell Research 13, 683-692 (2014). 
67. Risebro, C.A., Vieira, J.M., Klotz, L. \& Riley, P.R. Characterisation of the human embryonic and foetal epicardium during heart development. Development 142, 3630 (2015).

68. Katz, T.C., et al. Distinct Compartments of the Proepicardial Organ Give Rise to Coronary Vascular Endothelial Cells. Developmental cell 22, 639-650 (2012).

69. Tian, X., Pu, W.T. \& Zhou, B. Cellular Origin and Developmental Program of Coronary Angiogenesis. Circ Res 116, 515-530 (2015).

70. von Gise, A., et al. WT1 regulates epicardial epithelial to mesenchymal transition through $\beta$-catenin and retinoic acid signaling pathways. Developmental biology 356 , 421-431 (2011).

71. Kwee, L., et al. Defective development of the embryonic and extraembryonic circulatory systems in vascular cell adhesion molecule (VCAM-1) deficient mice. Development 121, 489-503 (1995).

72. Huang, G.N., et al. C/EBP Transcription Factors Mediate Epicardial Activation During Heart Development and Injury. Science 338, 1599 (2012).

73. Lepilina, A., et al. A Dynamic Epicardial Injury Response Supports Progenitor Cell Activity during Zebrafish Heart Regeneration. Cell 127, 607-619 (2006).

74. Wang, J., Cao, J., Dickson, A.L. \& Poss, K.D. Epicardial regeneration is guided by cardiac outflow tract and Hedgehog signalling. Nature 522, 226-230 (2015).

75. Smart, N., et al. De novo cardiomyocytes from within the activated adult heart after injury. Nature 474, 640-644 (2011).

76. Smart, N., et al. Thymosin beta 4 induces adult epicardial progenitor mobilization and neovascularization. Nature 445, 177-182 (2007).

77. Zhou, B., et al. Adult mouse epicardium modulates myocardial injury by secreting paracrine factors. The Journal of Clinical Investigation 121, 1894-1904 (2011).

78. Rui, L., et al. Extending the time window of mammalian heart regeneration by thymosin beta 4. Journal of Cellular and Molecular Medicine 18, 2417-2424 (2014).

79. Hagensen, M.K., Vanhoutte, P.M. \& Bentzon, J.F. Arterial endothelial cells: still the craftsmen of regenerated endothelium. Cardiovascular Research 95, 281 (2012).

80. He, L., et al. Genetic lineage tracing discloses arteriogenesis as the main mechanism for collateral growth in the mouse heart. Cardiovascular Research 109, 419 (2016).

81. Bayliss, P.E., et al. Chemical modulation of receptor signaling inhibits regenerative angiogenesis in adult zebrafish. Nat Chem Biol 2, 265-273 (2006).

82. Eyries, M., et al. Hypoxia-Induced Apelin Expression Regulates Endothelial Cell Proliferation and Regenerative Angiogenesis. Circulation Research 103, 432 (2008).

83. $\mathrm{Xu}, \mathrm{C}$., et al. Arteries are formed by vein-derived endothelial tip cells. Nature communications 5, 5758 (2014).

84. Zhou, B., et al. Adult mouse epicardium modulates myocardial injury by secreting paracrine factors. The Journal of Clinical Investigation 121, 1894-1904.

85. Kikuchi, K., et al. Retinoic Acid Production by Endocardium and Epicardium Is an Injury Response Essential for Zebrafish Heart Regeneration. Developmental cell 20, 
397-404 (2011).

86. Zangi, L., et al. An IGF1R-Dependent Pathway Drives Epicardial Adipose Tissue Formation After Myocardial Injury. Circulation (2016).

87. Zhou, B., et al. Thymosin beta 4 treatment after myocardial infarction does not reprogram epicardial cells into cardiomyocytes. Journal of Molecular and Cellular Cardiology 52, 43-47 (2012).

88. Kikuchi, K., et al. tcf21+ epicardial cells adopt non-myocardial fates during zebrafish heart development and regeneration. Development (2011).

89. González-Rosa, J.M., Peralta, M. \& Mercader, N. Pan-epicardial lineage tracing reveals that epicardium derived cells give rise to myofibroblasts and perivascular cells during zebrafish heart regeneration. Developmental biology 370, 173-186 (2012).

90. Stevens, S.M., Gise, A.v., VanDusen, N., Zhou, B. \& Pu, W.T. Epicardium is required for cardiac seeding by yolk sac macrophages, precursors of resident macrophages of the adult heart. Developmental biology 413, 153-159 (2016).

91. Ramjee, V., et al. Epicardial YAP/TAZ orchestrate an immunosuppressive response following myocardial infarction. The Journal of Clinical Investigation 127, 899-911 (2017).

92. Balmer, G.M., et al. Dynamic haematopoietic cell contribution to the developing and adult epicardium. Nature communications 5, 4054 (2014).

93. Cao, J., et al. Single epicardial cell transcriptome sequencing identifies Caveolin 1 as an essential factor in zebrafish heart regeneration. Development 143, 232 (2016).

94. Ruparelia, N., et al. Acute myocardial infarction activates distinct inflammation and proliferation pathways in circulating monocytes, prior to recruitment, and identified through conserved transcriptional responses in mice and humans. European Heart Journal 36, 1923-1934 (2015).

95. Frangogiannis, N.G. Regulation of the Inflammatory Response in Cardiac Repair. Circulation Research 110, 159-173 (2012).

96. Nahrendorf, M., et al. The healing myocardium sequentially mobilizes two monocyte subsets with divergent and complementary functions. The Journal of Experimental Medicine 204, 3037-3047 (2007).

97. Nahrendorf, M. \& Swirski, F.K. Abandoning M1/M2 for a Network Model of Macrophage Function. Circ Res 119, 414-417 (2016).

98. Shiraishi, M., et al. Alternatively activated macrophages determine repair of the infarcted adult murine heart. The Journal of Clinical Investigation 126, 2151-2166 (2016).

99. Zouggari, Y., et al. B lymphocytes trigger monocyte mobilization and impair heart function after acute myocardial infarction. Nat Med 19, 1273-1280 (2013).

100. Weirather, J., et al. Foxp3+ CD4+ T Cells Improve Healing After Myocardial Infarction by Modulating Monocyte/Macrophage Differentiation. Circulation Research 115, 5567 (2014).

101. Ma, Y., et al. Temporal neutrophil polarization following myocardial infarction. Cardiovascular Research 110, 51 (2016). 
102. Kyritsis, N., et al. Acute Inflammation Initiates the Regenerative Response in the Adult Zebrafish Brain. Science 338, 1353 (2012).

Inflammation is sufficient to initiate regeneration in the zebrafish brain

103. Karin, M. \& Clevers, H. Reparative inflammation takes charge of tissue regeneration. Nature 529, 307-315 (2016).

104. Aurora, Arin B. \& Olson, Eric N. Immune Modulation of Stem Cells and Regeneration. Cell Stem Cell 15, 14-25 (2014).

105. Burzyn, D., et al. A Special Population of Regulatory T Cells Potentiates Muscle Repair. Cell 155, 1282-1295.

106. Heredia, Jose E., et al. Type 2 Innate Signals Stimulate Fibro/Adipogenic Progenitors to Facilitate Muscle Regeneration. Cell 153, 376-388 (2013).

107. Zordan, P., et al. Macrophages commit postnatal endothelium-derived progenitors to angiogenesis and restrict endothelial to mesenchymal transition during muscle regeneration. Cell death \& disease 5, e1031 (2014).

108. Boulter, L., et al. Macrophage-derived Wnt opposes Notch signaling to specify hepatic progenitor cell fate in chronic liver disease. Nat Med 18, 572-579 (2012).

109. Lin, S.-L., et al. Macrophage Wnt7b is critical for kidney repair and regeneration. Proceedings of the National Academy of Sciences 107, 4194-4199 (2010).

110. Han, C., et al. Acute inflammation stimulates a regenerative response in the neonatal mouse heart. Cell Res 25, 1137-1151 (2015).

111. Aurora, A.B., et al. Macrophages are required for neonatal heart regeneration. The Journal of Clinical Investigation 124, 1382-1392 (2014).

\section{Macrophages are essential for regeneration in the neonatal mouse heart by modulation of neoangiogenesis}

112. Lavine, K.J., et al. Distinct macrophage lineages contribute to disparate patterns of cardiac recovery and remodeling in the neonatal and adult heart. Proceedings of the National Academy of Sciences 111, 16029-16034 (2014).

113. Godwin, J.W. \& Brockes, J.P. Regeneration, tissue injury and the immune response. Journal of Anatomy 209, 423-432 (2006).

114. Rienks, M., Papageorgiou, A.-P., Frangogiannis, N.G. \& Heymans, S. Myocardial Extracellular Matrix. Circulation Research 114, 872 (2014).

115. Bonnans, C., Chou, J. \& Werb, Z. Remodelling the extracellular matrix in development and disease. Nat Rev Mol Cell Biol 15, 786-801 (2014).

116. Vinarsky, V., Atkinson, D.L., Stevenson, T.J., Keating, M.T. \& Odelberg, S.J. Normal newt limb regeneration requires matrix metalloproteinase function. Developmental biology 279, 86-98 (2005).

117. Calve, S., Odelberg, S.J. \& Simon, H.-G. A transitional extracellular matrix instructs cell behavior during muscle regeneration. Developmental biology 344, 259-271 (2010).

118. Godwin, J.W. \& Rosenthal, N. Scar-free wound healing and regeneration in amphibians: Immunological influences on regenerative success. Differentiation 87, 
$66-75$ (2014).

119. Hu, N., Yost, H.J. \& Clark, E.B. Cardiac morphology and blood pressure in the adult zebrafish. The Anatomical Record 264, 1-12 (2001).

120. Yahalom-Ronen, Y., Rajchman, D., Sarig, R., Geiger, B. \& Tzahor, E. Reduced matrix rigidity promotes neonatal cardiomyocyte dedifferentiation, proliferation and clonal expansion. eLife 4, e07455 (2015).

121. Canseco, D.C., et al. Human Ventricular Unloading Induces Cardiomyocyte Proliferation. Journal of the American College of Cardiology 65, 892-900 (2015).

122. Chen, W.C.W., et al. Decellularized zebrafish cardiac extracellular matrix induces mammalian heart regeneration. Science Advances 2, e1600844 (2016).

123. Mercer, S.E., Odelberg, S.J. \& Simon, H.-G. A dynamic spatiotemporal extracellular matrix facilitates epicardial-mediated vertebrate heart regeneration. Developmental biology 382, 457-469 (2013).

124. Wang, J., Karra, R., Dickson, A.L. \& Poss, K.D. Fibronectin is deposited by injuryactivated epicardial cells and is necessary for zebrafish heart regeneration. Developmental biology 382, 427-435 (2013).

125. Shimazaki, M., et al. Periostin is essential for cardiac healingafter acute myocardial infarction. The Journal of Experimental Medicine 205, 295 (2008).

126. Kuhn, B., et al. Periostin induces proliferation of differentiated cardiomyocytes and promotes cardiac repair. Nat Med 13, 962-969 (2007).

127. Ladage, D., et al. Stimulating Myocardial Regeneration with Periostin Peptide in Large Mammals Improves Function Post-Myocardial Infarction but Increases Myocardial Fibrosis. PLOS ONE 8, e59656 (2013).

128. Yang, E.V., Gardiner, D.M., Carlson, M.R.J., Nugas, C.A. \& Bryant, S.V. Expression of Mmp-9 and related matrix metalloproteinase genes during axolotl limb regeneration. Developmental Dynamics 216, 2-9 (1999).

129. Hastings, C.L., et al. Drug and cell delivery for cardiac regeneration. Advanced Drug Delivery Reviews 84, 85-106 (2015).

130. Bely, A.E. \& Nyberg, K.G. Evolution of animal regeneration: re-emergence of a field. Trends in Ecology \& Evolution 25, 161-170 (2010).

131. Goss, R.J. The evolution of regeneration: Adaptive or inherent? Journal of Theoretical Biology 159, 241-260 (1992).

132. Furtado, M.B., Nim, H.T., Boyd, S.E. \& Rosenthal, N.A. View from the heart: cardiac fibroblasts in development, scarring and regeneration. Development 143, 387 (2016).

133. Kanisicak, O., et al. Genetic lineage tracing defines myofibroblast origin and function in the injured heart. Nature communications 7, 12260 (2016).

134. Lévesque, M., et al. Transforming Growth Factor: $\beta$ Signaling Is Essential for Limb Regeneration in Axolotls. PLOS ONE 2, e1227 (2007).

135. Satoh, A., Hirata, A. \& Makanae, A. Collagen Reconstitution is Inversely Correlated with Induction of Limb Regeneration in Ambystoma mexicanum. Zoological Science 29, 191-197 (2012). 
136. Anderson, M.A., et al. Astrocyte scar formation aids central nervous system axon regeneration. Nature 532, 195-200 (2016).

137. Bicknell, Katrina A., Coxon, Carmen H. \& Brooks, G. Forced expression of the cyclin B1-CDC2 complex induces proliferation in adult rat cardiomyocytes. Biochemical Journal 382, 411 (2004).

138. Di Stefano, V., Giacca, M., Capogrossi, M.C., Crescenzi, M. \& Martelli, F. Knockdown of Cyclin-dependent Kinase Inhibitors Induces Cardiomyocyte Re-entry in the Cell Cycle. Journal of Biological Chemistry 286, 8644-8654 (2011).

139. Chaudhry, H.W., et al. Cyclin A2 Mediates Cardiomyocyte Mitosis in the Postmitotic Myocardium. Journal of Biological Chemistry 279, 35858-35866 (2004).

140. Pasumarthi, K.B.S., Nakajima, H., Nakajima, H.O., Soonpaa, M.H. \& Field, L.J. Targeted Expression of Cyclin D2 Results in Cardiomyocyte DNA Synthesis and Infarct Regression in Transgenic Mice. Circulation Research 96, 110 (2005).

141. Ebelt, H., et al. E2F2 expression induces proliferation of terminally differentiated cardiomyocytes in vivo. Cardiovascular Research 80, 219 (2008).

142. Cheng, Y.Y., et al. Reprogramming- derived gene cocktail increases cardiomyocyte proliferation for heart regeneration. EMBO molecular medicine (2016).

143. Engel, F.B., Hsieh, P.C.H., Lee, R.T. \& Keating, M.T. FGF1/p38 MAP kinase inhibitor therapy induces cardiomyocyte mitosis, reduces scarring, and rescues function after myocardial infarction. Proceedings of the National Academy of Sciences 103, 1554615551 (2006).

144. Garbayo, E., et al. Catheter-based Intramyocardial Injection of FGF1 or NRG1-loaded MPs Improves Cardiac Function in a Preclinical Model of Ischemia-Reperfusion. Scientific Reports 6, 25932 (2016).

145. Zhao, L., et al. Notch signaling regulates cardiomyocyte proliferation during zebrafish heart regeneration. Proceedings of the National Academy of Sciences 111, 14031408 (2014).

146. Lenihan, D.J., et al. A Phase I, Single Ascending Dose Study of Cimaglermin Alfa (Neuregulin 1 $\beta 3$ ) in Patients With Systolic Dysfunction and Heart Failure. JACC: Basic to Translational Science 1, 576-586 (2016).

147. Eulalio, A., et al. Functional screening identifies miRNAs inducing cardiac regeneration. Nature 492, 376-381 (2012).

\section{MicroRNAs are involved in cardiac regeneration and have therapeutic effects to modulate repair in the mouse heart}

148. Tian, Y., et al. A microRNA-Hippo pathway that promotes cardiomyocyte proliferation and cardiac regeneration in mice. Science Translational Medicine 7, 279ra238 (2015).

149. Hesse, M., et al. Direct visualization of cell division using high-resolution imaging of M-phase of the cell cycle. Nature communications 3, 1076 (2012).

150. Srivastava, D. \& DeWitt, N. In Vivo Cellular Reprogramming: The Next Generation. Cell 166, 1386-1396 (2016).

151. Jopling, C., Boue, S. \& Belmonte, J.C.I. Dedifferentiation, transdifferentiation and reprogramming: three routes to regeneration. Nat Rev Mol Cell Biol 12, 79-89 (2011). 
152. Thorel, F., et al. Conversion of adult pancreatic alpha-cells to beta-cells after extreme beta-cell loss. Nature 464, 1149-1154 (2010).

153. Zhang, R., et al. In vivo cardiac reprogramming contributes to zebrafish heart regeneration. Nature 498, 497-501 (2013).

154. Yanger, K., et al. Robust cellular reprogramming occurs spontaneously during liver regeneration. Genes \& Development 27, 719-724 (2013).

155. Chong, J.J.H., et al. Human embryonic-stem-cell-derived cardiomyocytes regenerate non-human primate hearts. Nature 510, 273-277 (2014).

\section{Human ES-derived cardiomyocytes can engraft the macaque heart following MI}

156. Takahashi, K. \& Yamanaka, S. Induction of Pluripotent Stem Cells from Mouse Embryonic and Adult Fibroblast Cultures by Defined Factors. Cell 126, 663-676 (2006).

157. Shiba, Y., et al. Allogeneic transplantation of iPS cell-derived cardiomyocytes regenerates primate hearts. Nature 538, 388-391 (2016).

158. Efe, J.A., et al. Conversion of mouse fibroblasts into cardiomyocytes using a direct reprogramming strategy. Nat Cell Biol 13, 215-222 (2011).

159. leda, M., et al. Direct Reprogramming of Fibroblasts into Functional Cardiomyocytes by Defined Factors. Cell 142, 375-386 (2010).

\section{Fibroblasts can be directly reprogrammed into cardiomyocytes in vitro by Gata4, Mef2c and Tbx5}

160. Srivastava, D. \& Yu, P. Recent advances in direct cardiac reprogramming. Current Opinion in Genetics \& Development 34, 77-81 (2015).

161. Song, K., et al. Heart repair by reprogramming non-myocytes with cardiac transcription factors. Nature 485, 599-604 (2012).

\section{Key study demonstrating in vivo reprogramming to form new cardiomocytes}

162. Qian, L., et al. In vivo reprogramming of murine cardiac fibroblasts into induced cardiomyocytes. Nature 485, 593-598 (2012).

\section{Key study demonstrating in vivo reprogramming to form new cardiomocytes}

163. Jayawardena, T.M., et al. MicroRNA-Mediated In Vitro and In Vivo Direct Reprogramming of Cardiac Fibroblasts to Cardiomyocytes. Circulation Research 110, 1465 (2012).

164. Li, Y., et al. Tissue-engineered 3-dimensional (3D) microenvironment enhances the direct reprogramming of fibroblasts into cardiomyocytes by microRNAs. Scientific Reports 6, 38815 (2016).

165. Taimeh, Z., Loughran, J., Birks, E.J. \& Bolli, R. Vascular endothelial growth factor in heart failure. Nature Reviews Cardiology 10, 519-530 (2013).

166. Giacca, M. \& Zacchigna, S. VEGF gene therapy: therapeutic angiogenesis in the clinic and beyond. Gene Ther 19, 622-629 (2012).

167. Iyer, D., et al. Robust derivation of epicardium and its differentiated smooth muscle cell progeny from human pluripotent stem cells. Development 142, 1528-1541 (2015). 
168. Wei, K., et al. Epicardial FSTL1 reconstitution regenerates the adult mammalian heart. Nature 525, 479-485 (2015).

169. Zangi, L., et al. Modified mRNA directs the fate of heart progenitor cells and induces vascular regeneration after myocardial infarction. Nat Biotech 31, 898-907 (2013).

170. Mandic, L., et al. Molecular Imaging of Angiogenesis in Cardiac Regeneration. Current Cardiovascular Imaging Reports 9, 27 (2016).

171. Tian, X., et al. De novo formation of a distinct coronary vascular population in neonatal heart. Science 345, 90-94 (2014).

172. Miquerol, L., et al. Endothelial Plasticity Drives Arterial Remodeling Within the Endocardium After Myocardial Infarction. Circulation Research 116, 1765 (2015).

173. Norman, S. \& Riley, P.R. Anatomy and development of the cardiac lymphatic vasculature: Its role in injury and disease. Clinical Anatomy 29, 305-315 (2016).

174. Ishikawa, Y., et al. Lymphangiogenesis in myocardial remodelling after infarction. Histopathology 51, 345-353 (2007).

175. Klotz, L., et al. Cardiac lymphatics are heterogeneous in origin and respond to injury. Nature 522, 62-67 (2015).

176. Henri, O., et al. Selective Stimulation of Cardiac Lymphangiogenesis Reduces Myocardial Edema and Fibrosis Leading to Improved Cardiac Function Following Myocardial Infarction. Circulation (2016).

177. Ruparelia, N., Chai, J.T., Fisher, E.A. \& Choudhury, R.P. Inflammatory processes in cardiovascular disease: a route to targeted therapies. Nature Reviews Cardiology 14, 133-144 (2016).

178. Majmudar, M.D., et al. Monocyte-Directed RNAi Targeting CCR2 Improves Infarct Healing in Atherosclerosis-Prone Mice. Circulation 127, 2038 (2013).

179. Macrophages therapy for liver cirrhosis. (BioMed Central, ISRCTN registry).

180. Gourdie, R.G., Dimmeler, S. \& Kohl, P. Novel therapeutic strategies targeting fibroblasts and fibrosis in heart disease. Nature Reviews Drug Discovery 15, 620-638 (2016).

181. Talman, V. \& Ruskoaho, H. Cardiac fibrosis in myocardial infarction-from repair and remodeling to regeneration. Cell and Tissue Research 365, 563-581 (2016).

182. Galindo, C.L., et al. Anti-Remodeling and Anti-Fibrotic Effects of the Neuregulin-1 $\beta$ Glial Growth Factor 2 in a Large Animal Model of Heart Failure. Journal of the American Heart Association 3(2014).

183. Kanemitsu, H., et al. Chymase Inhibition Prevents Cardiac Fibrosis and Dysfunction after Myocardial Infarction in Rats. Hypertens Res 29, 57-64 (2006).

184. Hoshino, F., et al. Chymase inhibitor improves survival in hamsters with myocardial infarction. J Cardiovasc Pharmacol 41, S11-18 (2003).

185. Liu, C., et al. Platelet-derived growth factor blockade on cardiac remodeling following infarction. Molecular and Cellular Biochemistry 397, 295-304 (2014).

186. Menasche, P. Cardiac cell therapy: Lessons from clinical trials. Journal of Molecular and Cellular Cardiology 50, 258-265 (2011). 
187. Behfar, A., Crespo-Diaz, R., Terzic, A. \& Gersh, B.J. Cell therapy for cardiac repair lessons from clinical trials. Nature Reviews Cardiology 11, 232-246 (2014).

188. Alvarado, A.S. \& Tsonis, P.A. Bridging the regeneration gap: genetic insights from diverse animal models. Nat Rev Genet 7, 873-884 (2006).

189. Bujak, M., et al. Aging-Related Defects Are Associated With Adverse Cardiac Remodeling in a Mouse Model of Reperfused Myocardial Infarction. Journal of the American College of Cardiology 51, 1384-1392 (2008).

190. Choi, W.-Y., et al. In vivo monitoring of cardiomyocyte proliferation to identify chemical modifiers of heart regeneration. Development 140, 660 (2013).

191. Ruozi, G., et al. AAV-mediated in vivo functional selection of tissue-protective factors against ischaemia. Nature communications 6, 7388 (2015).

192. Plowright, A.T., Engkvist, O., Gill, A., Knerr, L. \& Wang, Q.-D. Heart Regeneration: Opportunities and Challenges for Drug Discovery with Novel Chemical and Therapeutic Methods or Agents. Angewandte Chemie International Edition 53, 40564075 (2014).

193. Willems, E., et al. A Chemical Biology Approach to Myocardial Regeneration. Journal of Cardiovascular Translational Research 4, 340-350 (2011).

194. Campbell, N.G. \& Suzuki, K. Cell Delivery Routes for Stem Cell Therapy to the Heart: Current and Future Approaches. Journal of Cardiovascular Translational Research 5, 713-726 (2012).

195. Qian, L., et al. Hemodynamic contribution of stem cell scaffolding in acute injured myocardium. Tissue Eng Part A 18, 1652-1663 (2012).

196. Saludas, L., Pascual-Gil, S., Prósper, F., Garbayo, E. \& Blanco-Prieto, M. Hydrogel based approaches for cardiac tissue engineering. International Journal of Pharmaceutics (2016).

197. Sarig, R. \& Tzahor, E. The cancer paradigms of mammalian regeneration: can mammals regenerate as amphibians? Carcinogenesis 38, 359-366 (2017).

198. Rosen, M.R., Myerburg, R.J., Francis, D.P., Cole, G.D. \& Marbán, E. Translating Stem Cell Research to Cardiac Disease Therapies: Pitfalls and Prospects for Improvement. Journal of the American College of Cardiology 64, 922-937 (2014).

199. Hare, J.M., et al. Phase II Clinical Research Design in Cardiology. Circulation 127, 1630 (2013).

200. Naumova, A.V., Modo, M., Moore, A., Murry, C.E. \& Frank, J.A. Clinical imaging in regenerative medicine. Nature biotechnology 32, 804-818 (2014).

201. Nowbar, A.N., et al. Discrepancies in autologous bone marrow stem cell trials and enhancement of ejection fraction (DAMASCENE): weighted regression and metaanalysis. BMJ 348, g2688 (2014).

202. ISSCR. Guidelines for stem cell science and clinical translation. (Skokie, IL, 2016).

203. Caulfield, T., Sipp, D., Murry, C.E., Daley, G.Q. \& Kimmelman, J. Confronting stem cell hype. Science 352, 776 (2016).

204. Swirski, F.K., et al. Identification of splenic reservoir monocytes and their deployment to inflammatory sites. Science 325, 612-616 (2009). 
205. Niccoli, G., Burzotta, F., Galiuto, L. \& Crea, F. Myocardial No-Reflow in Humans. Journal of the American College of Cardiology 54, 281-292 (2009).

206. Van Linthout, S., Miteva, K. \& Tschope, C. Crosstalk between fibroblasts and inflammatory cells. Cardiovascular Research 102, 258-269 (2014).

207. Pfeffer, M.A. \& Braunwald, E. Ventricular remodeling after myocardial infarction. Experimental observations and clinical implications. Circulation 81, 1161 (1990).

208. Sutton, M.G.S.J. \& Sharpe, N. Left Ventricular Remodeling After Myocardial Infarction. Circulation 101, 2981 (2000).

209. Packer, M. Pathophysiology of chronic heart failure. The Lancet 340, 88-92 (1992).

210. Lymperopoulos, A., Rengo, G. \& Koch, W.J. Adrenergic Nervous System in Heart Failure. Circulation Research 113, 739 (2013).

211. Narula, J., Haider, N., Arbustini, E. \& Chandrashekhar, Y. Mechanisms of Disease: apoptosis in heart failure - seeing hope in death. Nature Clinical Practice Cardiovascular Medicine 3, 681-688 (2006).

212. Packer, M. The neurohormonal hypothesis: A theory to explain the mechanism of disease progression in heart failure. Journal of the American College of Cardiology 20, 248-254 (1992).

213. Menasché, P., et al. Myoblast transplantation for heart failure. The Lancet 357, 279280 (2001).

214. Strauer, B.E., et al. Repair of Infarcted Myocardium by Autologous Intracoronary Mononuclear Bone Marrow Cell Transplantation in Humans. Circulation 106, 1913 (2002).

215. Perin, E.C., et al. Transendocardial, Autologous Bone Marrow Cell Transplantation for Severe, Chronic Ischemic Heart Failure. Circulation 107, 2294 (2003).

216. Wollert, K.C., et al. Intracoronary autologous bone-marrow cell transfer after myocardial infarction: the BOOST randomised controlled clinical trial. The Lancet 364, 141-148 (2004).

217. Lunde, K., et al. Intracoronary Injection of Mononuclear Bone Marrow Cells in Acute Myocardial Infarction. New England Journal of Medicine 355, 1199-1209 (2006).

218. Schächinger, V., et al. Intracoronary Bone Marrow-Derived Progenitor Cells in Acute Myocardial Infarction. New England Journal of Medicine 355, 1210-1221 (2006).

219. Janssens, S., et al. Autologous bone marrow-derived stem-cell transfer in patients with ST-segment elevation myocardial infarction: double-blind, randomised controlled trial. The Lancet 367, 113-121 (2006).

220. Menasché, P., et al. The Myoblast Autologous Grafting in Ischemic Cardiomyopathy (MAGIC) Trial. Circulation 117, 1189 (2008).

221. Bolli, R., et al. Cardiac stem cells in patients with ischaemic cardiomyopathy (SCIPIO): initial results of a randomised phase 1 trial. The Lancet 378, 1847-1857 (2011).

222. Makkar, R.R., et al. Intracoronary cardiosphere-derived cells for heart regeneration after myocardial infarction (CADUCEUS): a prospective, randomised phase 1 trial. The Lancet 379, 895-904 (2012). 
223. Perin, E.C., Willerson, J.T., Pepine, C.J. \& et al. Effect of transendocardial delivery of autologous bone marrow mononuclear cells on functional capacity, left ventricular function, and perfusion in chronic heart failure: The focus-cctrn trial. JAMA 307, 17171726 (2012).

224. Sürder, D., et al. Intracoronary Injection of Bone Marrow Derived Mononuclear Cells, Early or Late after Acute Myocardial Infarction: Effects on Global Left Ventricular Function Four months results of the SWISS-AMI trial. Circulation 127, 1968-1979 (2013).

225. Karantalis, V., et al. Autologous Mesenchymal Stem Cells Produce Concordant Improvements in Regional Function, Tissue Perfusion, and Fibrotic Burden When Administered to Patients Undergoing Coronary Artery Bypass Grafting: The Prospective Randomized Study of Mesenchymal Stem Cell Therapy in Patients Undergoing Cardiac Surgery (PROMETHEUS) trial. Circulation Research 114, 13021310 (2014).

226. Menasché, P., et al. Human embryonic stem cell-derived cardiac progenitors for severe heart failure treatment: first clinical case report. European Heart Journal 36, 2011-2017 (2015).

227. Choudry, F., et al. A randomized double-blind control study of early intra-coronary autologous bone marrow cell infusion in acute myocardial infarction: the REGENERATE-AMI clinical trial. European Heart Journal 37, 256-263 (2016).

228. Bagno, L.L., et al. Growth Hormone-Releasing Hormone Agonists Reduce Myocardial Infarct Scar in Swine With Subacute Ischemic Cardiomyopathy. Journal of the American Heart Association 4, e001464 (2015).

229. Koudstaal, S., et al. Sustained Delivery of Insulin-Like Growth Factor-1/Hepatocyte Growth Factor Stimulates Endogenous Cardiac Repair in the Chronic Infarcted Pig Heart. Journal of Cardiovascular Translational Research 7, 232-241 (2014).

230. Gao, R., et al. A Phase II, Randomized, Double-Blind, Multicenter, Based on Standard Therapy, Placebo-Controlled Study of the Efficacy and Safety of Recombinant Human Neuregulin-1 in Patients With Chronic Heart Failure. Journal of the American College of Cardiology 55, 1907-1914 (2010).

231. O'Donoghue, M.L., Glaser, R., Cavender, M.A. \& et al. Effect of losmapimod on cardiovascular outcomes in patients hospitalized with acute myocardial infarction: A randomized clinical trial. JAMA 315, 1591-1599 (2016).

232. Cerisano, G., et al. Early short-term doxycycline therapy in patients with acute myocardial infarction and left ventricular dysfunction to prevent the ominous progression to adverse remodelling: the TIPTOP trial. European Heart Journal 35, 184-191 (2013).

233. Abbate, A., et al. Effects of Interleukin-1 Blockade With Anakinra on Adverse Cardiac Remodeling and Heart Failure After Acute Myocardial Infarction [from the Virginia Commonwealth University-Anakinra Remodeling Trial (2) (VCU-ART2) Pilot Study]. The American Journal of Cardiology 111, 1394-1400 (2013).

234. Abbate, A., et al. Interleukin-1 Blockade With Anakinra to Prevent Adverse Cardiac Remodeling After Acute Myocardial Infarction (Virginia Commonwealth University Anakinra Remodeling Trial [VCU-ART] Pilot Study). American Journal of Cardiology 105, 1371-1377.e1371.

235. Gullestad, L., et al. Intravenous immunoglobulin does not reduce left ventricular remodeling in patients with myocardial dysfunction during hospitalization after acute myocardial infarction. International Journal of Cardiology 168, 212-218 (2013). 
236. Najjar, S.S., Rao, S.V., Melloni, C. \& et al. Intravenous erythropoietin in patients with st-segment elevation myocardial infarction: Reveal: a randomized controlled trial. JAMA 305, 1863-1872 (2011).

237. The, A.A.M.I.I. Pexelizumab for acute st-elevation myocardial infarction in patients undergoing primary percutaneous coronary intervention: A randomized controlled trial. JAMA 297, 43-51 (2007).

238. Hudson, M.P., et al. Effects of Selective Matrix Metalloproteinase Inhibitor (PG116800) to Prevent Ventricular Remodeling After Myocardial Infarction: Results of the PREMIER (Prevention of Myocardial Infarction Early Remodeling) Trial. Journal of the American College of Cardiology 48, 15-20 (2006).

\section{Acknowledgments}

T.J.C is supported by the Wellcome Trust (grant: $106334 / Z / 14 / Z)$. PRR is supported by the

British Heart Foundation (grants: $\mathrm{CH} / 11 / 1 / 28798$; RG/13/9/303269).

\section{Conflict of interest statement}

None to declare 


\section{Boxes}

\section{Box 1: Development of heart failure: pathophysiological mechanisms}

Heart failure following acute $\mathrm{Ml}$ is a paradigm for failed regeneration. Following coronary artery occlusion, ischaemic death of cardiomyocytes begins within hours. Cell injury and death trigger release of proinflammatory cytokines, infiltration of neutrophils and mobilisation of monocytes from the spleen. ${ }^{204}$ Opening of the occluded coronary artery by PPCl improves salvage of the injured myocardium, but in the short term leads to a burst of oxidative stress and further cardiomyocyte death. Even after reperfusion, microvascular obstruction (caused by thrombotic and plaque debris and by endothelial damage) persists in up to $50 \%$ of patients. ${ }^{205}$ Over subsequent days, inflammation drives further infarct expansion at the border zones. A transition from inflammation to repair is characterised by activation of fibroblasts to myofibroblasts, which deposit collagen matrix leading to scar formation. ${ }^{206}$

Chronic remodelling of the damaged left ventricle subsequently occurs over weeks to months, with ventricular dilatation, scar thinning and activation of interstitial fibrosis. ${ }^{207,208}$ Reduced cardiac output triggers activation of neurohormonal systems which act to maintain the circulation. ${ }^{209}$ Release of angiotensin II and aldosterone drive sodium and fluid retention, and adrenergic system activation maintains blood pressure through vasoconstriction. ${ }^{210}$ These mechanisms are initially compensatory but become maladaptive, driving fluid overload, myocardial hypertrophy, and slow but ongoing cardiomyocyte death, leading to further deterioration in ventricular function. ${ }^{211,212}$ Incremental benefits may be gained by optimising early salvage, no-reflow and further inhibition of maladaptive physiology, but entirely novel approaches are required to address the fundamental issue of cardiomyocyte death. 


\section{Figure Legends}

\section{Figure 1}

Heart failure therapy pipeline, to present day. In green: landmark breakthroughs in heart failure therapy, with key trials indicated by *. In purple: progress in regenerative therapies for heart failure. Abbreviations: ACEI - angiotensin converting enzyme inhibitors; ARB angiotensin receptor blockers; BB - beta-blockers; BMMCs - bone marrow mononuclear cells; CMs - cardiomyocytes; ES - embryonic stem cell; CRT - cardiac resynchronisation therapy; HF - heart failure; ICD - implantable cardioverter defibrillator; iPS - induced pluripotent stem cell; MRA - mineralocorticoid receptor antagonists; MSCs - mesenchymal stem cells.

\section{Figure 2}

Endogenous mechanisms controlling cardiomyocyte proliferation. Initiation of cardiomyocyte proliferation is regulated by both intrinsic and extrinsic factors. A number of soluble ligands have been identified which promote cardiomyocyte proliferation during development and in models of heart regeneration, including NRG1, FGF1, antagonists of Hippo, Wnts and TWEAK. Other soluble cues implicated in proliferation include OSM1, a macrophage-derived cytokine which directs cardiomyocyte de-differentiation. Downstream transcriptional regulators of cardiomyocyte cell-cycle re-entry include Hand2, Gata4, YAP/TAZ, Hif1 $\alpha$ and miRNAs. In the adult mammalian heart, cardiomyocytes exit the cell cycle postnatally and are resistant to cell cycle re-entry, with proliferation inhibited by p38MAPK, Meis1, miR15 and reactive oxygen species. Structural and functional aspects of the extracellular matrix also regulate cardiomyocyte proliferation: periostin and a lack of matrix rigidity promote cardiomyocyte proliferation. Factors which promote cytokinesis following binucleation, to generate new daughter cells, remain poorly defined.

\section{Figure 3}

\section{Therapeutic strategies for heart regeneration}

a) Strategies for replacement of cardiomyocytes (CMs). From top: (1) Reactivation of cardiomyocyte proliferation is the major mechanism by which endogenous regeneration 
occurs in the zebrafish and neonatal mouse, and has been achieved in preclinical models by targeting upstream ligands such as NRG1 and FGF1, and downstream cell cycle pathways mediated by Meis1, YAP/TAZ, p38MAPK, and miRNAs including has-miR-590, has-miR199a, and miR302-367. (2) Stimulation of progenitor populations such as the epicardium or cardiac progenitor cells (CPCs) leads to pleiotropic effects to support CM survival and proliferation, but current strategies do not appear to directly lead to new CMs in signficant numbers. (3) In vivo reprogramming of fibroblast to produce CMs has been achieved in preclinical models using defined transcription factor cocktails (e.g. GHMT) and microRNAs, and in vitro by small molecules. (4). Replacement of CMs by transplantation of exogenous mature CMs, derived from iPS cells or ES cells, have shown proof of concept in large animal studies.

b) Therapeutic targeting of the non-cardiomyocyte compartment for cardiac regeneration. (1) Epicardial activation (top right). During cardiac development and after injury, soluble factors derived from the activated epicardium supports angiogenesis, cardiomyocyte proliferation and survival, including FSTL1, FGF2 and VEGFa. Identifying factors (such as TB4) which activate or direct the epicardium to promote repair, or delivery of specific recombinant factors identified from the epicardium, are unexploited therapeutic strategies. (2) Angiogenesis (red vessels)/lymphangiogenesis (green vessels). Replacement of damaged vasculature will be vital to support new survival of transplanted, reprogrammed or proliferated CMs. Delivery of recombinant VEGFc, a macrophage-derived cytokine which promotes lymphangiogenesis, improves healing and functional outcome following MI in mice. (3) Immunomodulation (bottom right): inhibition of CCL2/CCR2 signalling in monocyte-macrophages by delivery of siRNA nanoparticles reduces monocyte infiltration and infarct size in mice. Signals from the epicardium have recently been identified which recruit regulatory $T$ cells to dampen inflammation following injury. (4) Fibrosis: (left): harnessing endogenous anti-fibrotic pathways mediated by NRG1 or relaxin may be harnessed to halt progression of remodelling and heart failure. Targeting pro-fibrotic pathways with inhibitors of PDGFR, Wnts, chymase or HDAC, have all shown promise in small animal models. Finally, in vivo reprogramming of fibroblasts into CMs, using GATA4, Hand2, Mef2c and Tbx5, may allow replacement of CMs, restoration of function and prevent fibrosis. Current therapeutic strategies shown in green, 
solid lines; endogenous signalling pathways shown in orange, dotted lines. 
Table 1: Landmark studies from the infancy of regeneration: cell therapy trials in acute myocardial infarction \& heart failure

\begin{tabular}{|c|c|c|c|c|c|c|c|}
\hline Name & Design & Patient group/no. & Cell type/dose/delivery route & Primary endpoint & Outcome(s) & Comment & Ref \\
\hline $\begin{array}{l}\text { Menasche et al } \\
2001\end{array}$ & Case report & $\begin{array}{l}\text { Ischaemic HF } \\
\text { undergoing CABG } \\
n=1\end{array}$ & $\begin{array}{l}\text { Skeletal myoblasts } \\
800 \times 10^{6} \text { cells } \\
\text { Intramyocardial injection during CABG }\end{array}$ & NA & NA & $\begin{array}{l}\text { First-in-man report of skeletal } \\
\text { myoblast injection. Improved wall } \\
\text { motion and perfusion on PET }\end{array}$ & 273 \\
\hline $\begin{array}{l}\text { Strauer et al } \\
2002\end{array}$ & $\begin{array}{l}\text { Non-randomised } \\
\text { Open label }\end{array}$ & $\begin{array}{l}\text { Acute MI } \\
\mathrm{n}=20\end{array}$ & $\begin{array}{l}\text { Autologous BM cells } \\
2.8 \times 10^{7} \text { cells } \\
\text { Intracoronary delivery }\end{array}$ & Not specified & $\begin{array}{l}\text { Reduced infarct size in } \\
\text { cell therapy arm }\end{array}$ & First study of BM cells in acute MI & \\
\hline $\begin{array}{l}\text { Perin et al } \\
2003\end{array}$ & $\begin{array}{l}\text { Non-randomised } \\
\text { Open label }\end{array}$ & $\begin{array}{l}\begin{array}{l}\text { Ischaemic HF } \\
\mathrm{n}=21\end{array}\end{array}$ & $\begin{array}{l}\text { Autologous BM mononuclear cells } \\
\text { Mean } 25.5 \pm 6.3 \times 10^{6} \text { cells } \\
\text { Transendocardial injection }\end{array}$ & Safety & $\begin{array}{l}\text { Improved LV function, } \\
\text { reduced reversible } \\
\text { perfusion defect }\end{array}$ & First study of BM cells in HF & \\
\hline $\begin{array}{l}\text { BOOST } \\
2004\end{array}$ & $\begin{array}{l}\text { Randomised } \\
\text { Non-placebo controlled }\end{array}$ & $\begin{array}{l}\text { Acute MI } \\
\mathrm{n}=60\end{array}$ & $\begin{array}{l}\text { Autologous BM cells } \\
24.6 \times 10^{8} \text { nucleated cells } \\
\text { Intracoronary delivery }\end{array}$ & Change in LVEF & $\begin{array}{l}\text { Improved global LV } \\
\text { function }\end{array}$ & First randomised study of BM cells & 216 \\
\hline $\begin{array}{l}\text { ASTAMI } \\
2006\end{array}$ & $\begin{array}{l}\text { Randomised } \\
\text { Non-placebo controlled }\end{array}$ & $\begin{array}{l}\text { Acute MI } \\
\mathrm{n}=100\end{array}$ & $\begin{array}{l}\text { Autologous BM mononuclear cells } \\
\text { Median } 68 \times 10^{6} \text { cells } \\
\text { Intracoronary delivery }\end{array}$ & Change in LVEF & $\begin{array}{l}\text { No change in LVEF or } \\
\text { LVEDV or IS at } 6 \text { months }\end{array}$ & $\begin{array}{l}\text { Negative trial concurrent with } \\
\text { REPAIR-AMI }\end{array}$ & \\
\hline $\begin{array}{l}\text { REPAIR-AMI } \\
2006\end{array}$ & $\begin{array}{l}\text { Randomised } \\
\text { Double blind } \\
\text { Placebo controlled }\end{array}$ & $\begin{array}{l}\text { Acute MI } \\
\mathrm{n}=204\end{array}$ & $\begin{array}{l}\text { Autologous BM progenitor cells } \\
236 \times 10^{6} \text { cells } \\
\text { Intracoronary delivery }\end{array}$ & Change in LVEF & $\begin{array}{l}\text { Significant improvement } \\
\text { in global LV function at } 4 \\
\text { months }\end{array}$ & $\begin{array}{l}\text { Largest trial of BMCs. Showed } \\
\text { reduction in clinical endpoint of } \\
\text { death, recurrent MI \& revasc }\end{array}$ & \\
\hline $\begin{array}{l}\text { Janssens et al } \\
2006\end{array}$ & $\begin{array}{l}\text { Randomised } \\
\text { Double blind } \\
\text { Placebo controlled }\end{array}$ & $\begin{array}{l}\text { Acute MI } \\
\mathrm{n}=67\end{array}$ & $\begin{array}{l}\text { Autologouns BM stem cells } \\
304 \times 10^{6} \text { nucleated cells } \\
\text { Intracoronary delivery }\end{array}$ & Change in LVEF & $\begin{array}{l}\text { Negative for primary } \\
\text { endpoint }\end{array}$ & Reduction in infarct volume & 219 \\
\hline $\begin{array}{l}\text { MAGIC } \\
2008\end{array}$ & $\begin{array}{l}\text { Randomised } \\
\text { Double blind } \\
\text { Placebo controlled }\end{array}$ & $\begin{array}{l}\text { HF \& previous MI } \\
\text { undergoing CABG } \\
\mathrm{n}=97\end{array}$ & $\begin{array}{l}\text { Skeletal myoblasts } \\
400 \text { (low dose) }-800 \text { (high dose) } \times 10^{6} \text { cells } \\
\text { Surgical injection during } C A B G\end{array}$ & $\begin{array}{l}\text { Change in regional and } \\
\text { global LV function }\end{array}$ & $\begin{array}{l}\text { Negative for primary } \\
\text { efficacy endpoints }\end{array}$ & $\begin{array}{l}\text { High cell dose arm had reduced LV } \\
\text { remodelling with decreased LV } \\
\text { volumes. Increased arrhythmias in } \\
\text { the cell therapy arms. }\end{array}$ & 220 \\
\hline $\begin{array}{l}\text { SCIPIO* }^{*} \\
2011\end{array}$ & $\begin{array}{l}\text { Randomised } \\
\text { Open label } \\
\text { Non-placebo controlled }\end{array}$ & $\begin{array}{l}\text { Ischaemic HF } \\
\mathrm{n}=23\end{array}$ & $\begin{array}{l}\text { Autologous c-kit+ cardiac stem cells } \\
1 \times 10^{6} \text { cells } \\
\text { Intracoronary delivery }\end{array}$ & Safety & $\begin{array}{l}\text { No adverse events } \\
\text { reported }\end{array}$ & $\begin{array}{l}\text { Increase in LVEF and decrease in } \\
\text { infarct size reported in cell therapy } \\
\text { recipients (secondary endpoints) }\end{array}$ & 221 \\
\hline $\begin{array}{l}\text { CADUCEUS } \\
2012\end{array}$ & $\begin{array}{l}\text { Randomised } \\
\text { Non-placebo controlled }\end{array}$ & $\begin{array}{l}\text { Acute MI } \\
\mathrm{n}=25\end{array}$ & $\begin{array}{l}\text { Cardiosphere-derived cells } \\
12.5-25 \times 10^{6} \text { cells } \\
\text { Intracoronary delivery }\end{array}$ & $\begin{array}{l}\text { Safety: arrhythmic or } \\
\text { unexpected death, MI, } \\
\text { tumour formation or } \\
\text { MACE }\end{array}$ & Met safety endpoint & $\begin{array}{l}\text { Reduction in scar size/mass in cell } \\
\text { therapy arm }\end{array}$ & 222 \\
\hline $\begin{array}{l}\text { FOCUS-CCRTN } \\
2012\end{array}$ & $\begin{array}{l}\text { Randomised } \\
\text { Double blind } \\
\text { Placebo controlled }\end{array}$ & $\begin{array}{l}\begin{array}{l}\text { Ischaemic } \mathrm{HF} \\
\mathrm{n}=92\end{array}\end{array}$ & $\begin{array}{l}\text { Autologous BM stem cells } \\
100 \times 10^{6} \text { cells } \\
\text { Transendocardial injection }\end{array}$ & $\begin{array}{l}\text { Change in LV end- } \\
\text { systolic volume; maximal } \\
\text { O2 consumption, } \\
\text { reversibility on SPECT }\end{array}$ & $\begin{array}{l}\text { Negative for primary } \\
\text { endpoints }\end{array}$ & & 23 \\
\hline $\begin{array}{l}\text { SWISS-AMI } \\
2013\end{array}$ & $\begin{array}{l}\text { Randomised } \\
\text { Open label } \\
\text { Non-placebo controlled }\end{array}$ & $\begin{array}{l}\text { Acute MI } \\
\mathrm{n}=200\end{array}$ & $\begin{array}{l}\text { Autologous BM mononuclear cells } \\
140-160 \times 10^{6} \text { nucleated cells } \\
\text { Intracoronary delivery either early (5-7 days) } \\
\text { or late (3-4 weeks) after MI }\end{array}$ & Change in LVEF & $\begin{array}{l}\text { Negative for primary } \\
\text { endpoint }\end{array}$ & & \\
\hline $\begin{array}{l}\text { PROMETHEUS } \\
2014\end{array}$ & $\begin{array}{l}\text { Non-randomised } \\
\text { Non-placebo controlled }\end{array}$ & $\begin{array}{l}\text { Ischaemic HF } \\
\text { undergoing CABG } \\
n=6\end{array}$ & $\begin{array}{l}\text { Mesenchymal stem cells } \\
2 \times 10^{7} \text { (low dose) - } 2 \times 10^{8} \text { (high dose) cells } \\
\text { Intramyocardial injection during CABG }\end{array}$ & NA & NA & $\begin{array}{l}\text { Increased EF, decreased scar } \\
\text { mass }\end{array}$ & \\
\hline $\begin{array}{l}\text { Menasche et al. } \\
2015\end{array}$ & Case report & $\begin{array}{l}\text { Ischaemic HF } \\
\text { undergoing CABG } \\
n=1\end{array}$ & $\begin{array}{l}\text { Human ES-derived cardiac progenitor cells on } \\
\text { a fibrin scaffold } \\
\text { Surgical patch implantation }\end{array}$ & NA & NA & $\begin{array}{l}\text { First in man study. New onset } \\
\text { contractility observed in the } \\
\text { patched region }\end{array}$ & \\
\hline $\begin{array}{l}\text { REGENERATE-AMI } \\
2016\end{array}$ & $\begin{array}{l}\text { Randomised } \\
\text { Double blind } \\
\text { Placebo controlled }\end{array}$ & $\begin{array}{l}\text { Acute Ml } \\
\mathrm{n}=100\end{array}$ & $\begin{array}{l}\text { Autologous BM-derived cells } \\
59.8 \times 10^{6} \text { cells } \\
\text { Intracoronary delivery }\end{array}$ & Change in LVEF & $\begin{array}{l}\text { Negative for primary } \\
\text { endpoint }\end{array}$ & $\begin{array}{l}\text { Large, double-blinded study of } \\
\text { autologous BM cells which failed to } \\
\text { meet primary efficacy endpoint }\end{array}$ & 227 \\
\hline
\end{tabular}

Abbreviations: BM - bone marrow; ES - embryonic stem; CABG - coronary artery bypass grafting; HF - heart failure; LVEF - left ventricular ejection fraction; MACE - major adverse cardiovascular events; NA - not applicable; PET - positron emission tomography, SPECT - single-photon emission computed tomography; ${ }^{*}$ subject to expression of concern 
Table 2: Translational pipeline: preclinical large animal regeneration studies in heart failure following myocardial infarction

\begin{tabular}{|c|c|c|c|c|c|}
\hline Drug/therapy & Mechanism & Model/Delivery & Outcome & Comment & Ref \\
\hline Human ES-derived CMs & Direct CM replacement & $\begin{array}{l}\mathrm{HF}(2 \text { weeks post-I/R) } \\
\text { Surgical intramyocardial injection }\end{array}$ & $\begin{array}{l}\text { Successful transplantation, electromechanical } \\
\text { integration and partial maturation of ES-derived } \\
\text { CMs } \\
\text { No significant change in LVEF }\end{array}$ & $\begin{array}{l}\text { First study to demonstrate regeneration by } \\
\text { transplantation of CMs. All transplanted animals } \\
\text { experienced ventricular arrhythmias }\end{array}$ & \\
\hline Allogeneic iPS-derived CMs & Direct CM replacement & $\begin{array}{l}\mathrm{HF}(2 \text { weeks post-I/R) } \\
\text { Surgical intramyocardial injection }\end{array}$ & $\begin{array}{l}\text { Significant improvement in LVEF ( 10\%) at } 12 \\
\text { weeks }\end{array}$ & $\begin{array}{l}\text { Proof of principle study. All transplanted animals } \\
\text { experienced sustained ventricular tachycardia } \\
\text { peaking at day } 14 \text { post-transplantation }\end{array}$ & 157 \\
\hline $\begin{array}{l}\text { FGF1 \& NRG1-loaded } \\
\text { microparticles }\end{array}$ & $\begin{array}{l}\text { Angiogenesis } \\
\text { Reversal of fibrosis }\end{array}$ & $\begin{array}{l}\text { HF (4 weeks post-I/R) } \\
\text { Catheter-based transendocardial injection }\end{array}$ & $\begin{array}{l}\text { Approximate } 8-10 \% \text { improvement in fractional } \\
\text { shortening with both NRG1 \& FGF1 } \\
\text { microparticles }\end{array}$ & Reduced ventricular remodelling observed & 144 \\
\hline MR- 409 (GHRH agonist) & $\begin{array}{l}\text { Pleiotropic effects } \\
\text { Activation of the GH/GF-1 axis }\end{array}$ & $\begin{array}{l}\text { HF (2 weeks post-I/R) } \\
\text { Subcutaneous injection }\end{array}$ & Reduced scar size after 4 weeks & Not accompanied by improved cardiac function & 28 \\
\hline Recombinant FSTL1 in patch & $\begin{array}{l}\text { Pleiotropic effects } \\
\text { Stimulation of CM proliferation } \\
\text { Arteriogenesis }\end{array}$ & $\begin{array}{l}\mathrm{HF} \text { (1 week post I/R) } \\
\text { Surgical patch implantation }\end{array}$ & Approximate $10 \%$ improvement in LVEF & & \\
\hline IGF1 \& HGF within hydrogel & $\begin{array}{l}\text { Stimulation of CM proliferation } \\
\text { Angiogenesis }\end{array}$ & $\begin{array}{l}\text { HF (4 weeks post-I/R) } \\
\text { Catheter-based transendocardial injection }\end{array}$ & $\begin{array}{l}\text { Small improvement in LVEF } \\
\text { Reduced scar formation }\end{array}$ & $\begin{array}{l}\text { Overall small functional effects observed; trend } \\
\text { towards reduced fibrosis }\end{array}$ & 229 \\
\hline
\end{tabular}

Abbreviations: ES - embryonic stem (cell); I/R - ischaemia/reperfusion; LVEF - left ventricular ejection fraction; GHRH - growth hormone releasing hormone; GH - growth hormone; HGF _ hepatocyte growth factor; IGF-1 - insulin-like growth factor 1; iPS - induced pluripotent (stem cell); CM - cardiomyocyte 
Table 3: Recent clinical trials targeting cardiac injury and repair after acute myocardial infarction

\begin{tabular}{|c|c|c|c|c|c|c|}
\hline Trial & Drug & Mechanism & Phase/ Patient cohort & Primary Endpoint(s) & Outcome & Ref \\
\hline Lenihan et al 2016 & Cimaglermin- $\alpha$ & $\begin{array}{l}\text { Recombinant full } \\
\text { length neuregulin } \\
1 \beta 3\end{array}$ & $\begin{array}{l}\text { Phase I } \\
40 \text { patients with } \\
\text { symptomatic } \mathrm{HF} \text { and } \\
\text { LVEF } \leq 40 \% \text {. HF } \\
\text { aetiology not reported }\end{array}$ & Safety/tolerability & $\begin{array}{l}\text { No severe adverse effects. Improvement in LVEF in the high-dose } \\
\text { groups }(\sim 7-9 \%) \text { lasting for study duration ( } 90 \text { days) }\end{array}$ & 146 \\
\hline Gao et al 2010 & Neucardin & $\begin{array}{l}\text { Recombinant } \\
\text { epidermal growth } \\
\text { factor-like domain } \\
\text { of } \\
\text { neuregulin-1 } \beta\end{array}$ & $\begin{array}{l}\text { Phase II } \\
44 \text { patients with } \\
\text { symptomatic } \mathrm{HF} \text { and } \\
\mathrm{LVEF} \leq 40 \% \text {. HF } \\
\text { aetiology not reported }\end{array}$ & $\begin{array}{l}\text { Change in LVEF, end-systolic } \\
\text { volume, or end-diastolic volume } \\
\text { at } 90 \text { days }\end{array}$ & $\begin{array}{l}\text { Non-significant trend towards improved LVEF and reduced LV } \\
\text { remodelling in the neuregulin arms }\end{array}$ & 230 \\
\hline LATITUDE-TIMI 60 & Losmapimod & $\begin{array}{l}\text { P38 MAP kinase } \\
\text { inhibitor }\end{array}$ & $\begin{array}{l}\text { Phase III } \\
3503 \text { patients with ACS }\end{array}$ & $\begin{array}{l}\text { Major adverse cardiovascular } \\
\text { events at } 24 \text { weeks }\end{array}$ & No significant difference in primary endpoint or $\mathrm{HF}$ events & 231 \\
\hline TIPTOP & Doxycycline & Oral MMP inhibitor & $\begin{array}{l}\text { Phase II } \\
110 \text { patients with STEMI }\end{array}$ & Change in LVEDVI at 6 months & Significant reduction in LVEDVI and infarct size with doxycycline & 232 \\
\hline VCU-ART2 & Anakinra & $\begin{array}{l}\text { IL1-receptor } \\
\text { antagonist }\end{array}$ & $\begin{array}{l}\text { Phase II } \\
30 \text { patients with STEMI }\end{array}$ & Change in LVESVI at 3 months & $\begin{array}{l}\text { No signficant change in LVESVI, LVEDVI or LVEF. } \\
\text { Combined data from VCU-ART2 \& VCU-ART suggested a } \\
\text { reduction in HF events in the anakinra arm. Larger trial (VCU- } \\
\text { ART3) currently recruiting }\end{array}$ & 233 \\
\hline VCU-ART & Anakinra & $\begin{array}{l}\text { IL1-receptor } \\
\text { antagonist }\end{array}$ & $\begin{array}{l}\text { Phase II pilot } \\
10 \text { patients with STEMI }\end{array}$ & Change in LVESVI at 3 months & Significant improvement in LVESVi on cardiac MRI & 234 \\
\hline Gullestad et a/2013 & IVIG & Immunomodulation & $\begin{array}{l}\text { Phase II } \\
\text { 62 STEMI patients }\end{array}$ & Change in LVEF at 6 months & No significant difference in change in LVEF or scar size & 235 \\
\hline REVEAL & Erythropoietin & $\begin{array}{l}\text { Pleiotropic effects } \\
\text { on injury/repair }\end{array}$ & $\begin{array}{l}\text { Phase II } \\
222 \text { patients with STEMI }\end{array}$ & Infarct size & $\begin{array}{l}\text { No significant difference in infarct size. Increased rate of adverse } \\
\text { events with erythropoietin. }\end{array}$ & 236 \\
\hline APEX AMI & Pexelizumab & $\begin{array}{l}\text { Humanised } \\
\text { monoclonal } \\
\text { antibody } \\
\text { neutralising C5 } \\
\text { component of } \\
\text { complement }\end{array}$ & $\begin{array}{l}\text { Phase III } \\
5,745 \text { patients with } \\
\text { STEMI }\end{array}$ & All-cause mortality at 30 days & $\begin{array}{l}\text { No significant difference in mortality, or in secondary composite } \\
\text { endpoint of death, shock or } \mathrm{HF} \text { at } 30 \text { and } 90 \text { days }\end{array}$ & 237 \\
\hline PREMIER & PG-116800 & Oral MMP inhibitor & $\begin{array}{l}\text { Phase II } \\
253 \text { patients with STEMI } \\
\text { \& impaired LV function } \\
\text { (LVEF } 15-40 \% \text { ) }\end{array}$ & Change in LVEDVI at 90 days & No significant difference in LVEDVI after 30 or 90 days & \\
\hline
\end{tabular}

Abbreviations: ACS - acute coronary syndrome; CMs - cardiomyocytes; HF - heart failure; LVEF - left ventricular ejection fraction; iPS - induced pluripotent (stem cell); LVEDVI - left ventricular end-diastolic volume index; LVESVI - left ventricular end-systolic volume index; MI - myocardial infarction; MMP - matrix metalloproteinase; PCl - percutaneous coronary intervention; STEMI - STelevation myocardial infarction 
Glossary:

Autologous: derived from cells/tissues of the same individual

Allogeneic: derived from genetically different individuals from the same species

Binucleation: division of the nucleus leading to formation of two nuclei within a cell, without division of the cytoplasm

Cytokinesis: division of the cell cytoplasm to complete the cell cycle and create a membrane barrier between two daughter cells

Embryonic stem (ES) cells: pluripotent stem cells that are derived from the inner cell mass of human embryos

Epicardium: the outer layer of the heart, also known as the visceral pericardium

Fibrosis: a pathological process characterised by deposition of interstitial fibrous or scar tissue

Heart failure: a pathological state defined by the inability of the heart to pump blood to support the requirements of the body. Typical symptoms include shortness of breath, fluid retention and fatigue

Induced pluripotent stem (iPS) cells: pluripotent stem cells that are reprogrammed from somatic cells by introducing pluripotency factors

Lymphangiogenesis: the growth of new lymphatic vessels

Ploidy: the number of sets of chromosomes in a cell

Myocardial infarction (heart attack): acute injury to the heart caused by occlusion of the coronary blood supply, usually due to atherosclerotic plaque rupture

Remodelling: a process characterised by a change in size, shape and structure of the ventricle. After MI, pathological remodelling causes the ventricle to enlarge, become spherical in shape, and functionally deteriorate 


\section{Author biographies}

Thomas J. Cahill is a Cardiology Specialist Registrar and Wellcome Trust Doctoral Fellow based at the University of Oxford and Oxford Heart Centre, John Radcliffe Hospital. He read Natural Sciences at the University of Cambridge before studying clinical medicine at University College London. His doctoral research focuses on mechanisms of cardiac regeneration and repair, specifically the roles of macrophages and inflammation.

Robin P. Choudhury is Professor of Cardiovascular Medicine at the University of Oxford, where he is director of the Acute Vascular Imaging Centre and an interventional cardiologist. His training was in Oxford, London, and New York. He is a Fellow of Balliol College and of the Royal College of Physicians. His interests are in the characterization of patients with atherosclerosis and vascular inflammation and in particular in the development, validation, and application of new approaches to vascular imaging. He is the principal investigator of the Tripartite Immunometabolism Consortium.

Paul R. Riley took up the Chair of Development and Cell Biology in the Department of Physiology, Anatomy and Genetics in 2011, having been awarded a British Heart Foundation Personal Chair of Regenerative Medicine. He is also director of the virtual BHF Oxbridge Centre for Regenerative Medicine. He was formerly Professor of Molecular Cardiology at the UCL Institute of Child Health, London, where he was a principal investigator within the Molecular Medicine Unit for 12 years. His research interests are in cardiovascular development and regeneration.

\section{Key points}

Endogenous regeneration seen in animal models provides a template for optimal repair of the human heart following MI.

In the regenerating heart new cardiomyocytes are produced by proliferation of the existing cardiomyocyte pool. Understanding and targeting the intrinsic mechanisms which regulate cardiomyocyte cell cycle re-entry could enable therapeutic regeneration in the human heart. 
Repair is modulated by epicardial activation, neoangiogenesis, the immune response and the extracellular matrix. Biological insights from regenerative models, combined with use of highthroughput phenotypic screens and in vivo discovery approaches, are uncovering novel therapeutic targets and compounds to improve repair.

Regenerative strategies emerging from increased understanding of cardiomyocyte lineage specification include transplantation of in vitro-produced cardiomyocytes and in vivo reprogramming of fibroblasts. Current efforts to improve engraftment, maturation, and targeting will enable a next generation of trials.

Distinct approaches are required for patients in the immediate post-MI period and for those with chronic $\mathrm{HF}$, and high risk strategies should be targeted at the latter group. Clinical trial design should be tailored to incorporate informed biological endpoints alongside functional endpoints.

\section{TOC}

Regeneration of the heart by cardiomyocyte reconstitution represents an attractive approach to treat heart failure. Here, Riley and colleagues discuss recent insights into the biology of heart regeneration and highlight emerging therapeutic regenerative strategies for HF.

Challenges and considerations in the translation of regenerative therapies into the clinic are discussed. [Au:OK?]

\section{Subject categories}

Biological sciences / Drug discovery [URI /631/154]

Biological sciences / Physiology / Cardiovascular biology / Cardiovascular diseases [URI /631/443/592/75]

Biological sciences / Biotechnology / Regenerative medicine [URI /631/61/490] 
